\title{
24. ANELASTIC STRAIN RECOVERY AND ELASTIC PROPERTIES OF OCEANIC BASALTIC ROCKS ${ }^{1}$
}

\author{
N. R. Brereton, ${ }^{2}$ P. N. Chroston, ${ }^{3}$ C. J. Evans, ${ }^{2}$ J. A. Hudson, ${ }^{4}$ and R. B. Whitmarsh ${ }^{5}$
}

\begin{abstract}
A knowledge of rock stress is fundamental for improving our understanding of oceanic crustal mechanisms and lithospheric dynamic processes. However, direct measurements of stress in the deep oceans, and in particular stress magnitudes, have proved to be technically difficult.

Anelastic strain recovery measurements were conducted on 15 basalt core samples from Sites 765 and 766 during Leg 123. Three sets of experiments were performed: anelastic strain recovery monitoring, dynamic elastic property measurements, and thermal azimuthal anisotropy observations. In addition, a range of other tests and observations were recorded to characterize each of the samples.

One common feature of the experimental results and observations is that apparently no consistent orientation trend exists, either between the different measurements on each core sample or between the same sets of measurements on the various core samples. However, some evidence of correspondence between velocity anisotropy and anelastic strain recovery exists, but this is not consistent for all the core samples investigated.

Thermal azimuthal anisotropy observations, although showing no conclusive correlations with the other results, were of significant interest in that they clearly exhibited anisotropic behavior. The apparent reproducibility of this behavior may point toward the possibility of rocks that retain a "memory" of their stress history, which could be exploited to derive stress orientations from archived core.

Anelastic strain recovery is a relatively new technique. Because use of the method has extended to a wider range of rock types, the literature has begun to include examples of rocks that contracted with time. Strong circumstantial evidence exists to suggest that core-sample contractions result from the slow diffusion of pore fluids from a preexisting microcrack structure that permits the rock to deflate at a greater rate than the expansion caused by anelastic strain recovery. Both expansions and contractions of the Leg 123 cores were observed.

The basalt cores have clearly been intersected by an abundance of preexisting fractures, some of which pass right through the samples, but many are intercepted or terminate within the rock matrix. Thus, the behavior of the core samples will be influenced not only by the properties of the rock matrix between the fractures, but also by how these macro- and micro-scale fractures mutually interact. The strain-recovery curves recorded during Leg 123 for each of the 15 basalt core samples may reflect the result of two competing time dependent processes: anelastic strain recovery and pore pressure recovery. Were these the only two processes to influence the gauge responses, then one might expect that given the additional information required, established theoretical models might be used to determine consistent stress orientations and reliable stress magnitudes. However, superimposed upon these competing processes is their respective interaction with the preexisting fractures that intersect each core. Evidence from our experiments and observations suggests that these fractures have a dominating influence on the characteristics of the recovery curves and that their effects are complex.
\end{abstract}

\section{INTRODUCTION}

The lithosphere is subject to a variety of forces, both internal and external, that cause it to be stressed. These stresses determine the lithospheric dynamic response, for example faulting and earthquakes, but at the same time reflect the motions of the lithospheric plates relative to the asthenosphere. In a recent review, Zoback et al. (1989) summarized the principal sources of tectonic stress as ridge push, slab pull, trench suction, and shear traction (driving or braking) on the underside of the plates. Less significant, and sometimes more localized, sources of stress include the resistance caused by continent-continent collision, gravitational loads of volcanic and sedimentary origin, flexure in the vicinity of subduction zones, thermoelasticity (cooling), and membrane stresses associated mainly with latitudinal plate motions.

\footnotetext{
${ }^{1}$ Gradstein, F. M., Ludden, J. N., et al., 1992. Proc. ODP, Sci. Results, 123: College Station, TX (Ocean Drilling Program).

British Geological Survey, Keyworth, Nottingham, U.K.

${ }^{3}$ School of Environmental Sciences, University of East Anglia, Norwich, U.K.

${ }^{4}$ Department of Mineral Resources Engineering, Imperial College of Science and Technology, London, U.K.

${ }^{5}$ Institute of Oceanographic Sciences, Deacon Laboratory, Wormley, Godalming, U.K.
}

Stress is transmitted laterally throughout the relatively rigid plates, whether they lie under oceans or continents. Therefore, in studies of global stress patterns, land-based measurements can sometimes be used to predict stress in oceanic regions. There are many situations, however, where this approach is inappropriate, such as when determining the stress near accreting plate boundaries; oceanward of trenches; at multiple ridge, trench, or transform intersections; in the vicinity of seamount chains; and in regions of anomalous oceanic intraplate tectonics. In these circumstances, observations of the oceanic lithosphere itself are required to understand and predict tectonic processes.

Virtually the only source of information for the oceanic crust has been from earthquake fault plane solutions, which tend not only to be deep-seated and relatively infrequent, but also to be concentrated in the vicinity of the tectonically active areas of plate boundaries. There is, therefore, still a great paucity of stress information from the tectonically stable regions of oceanic plates.

Until recently, the experimental determination of in-situ rock stresses has been difficult. A range of rock-stress measurement techniques are available, but most have been developed by the mining industry for use in relatively shallow boreholes or in exposed rock faces and thus are inappropriate in the oceanic domain. These techniques differ considerably in their scale of measurement (i.e., the volume of rock and type of discontinuities over which the measurements are performed) and in the assump- 
tions behind their application. The most suitable for use in deepocean boreholes are hydraulic fracturing and borehole breakouts (Zoback et al., 1985; Newmark et al., 1985; Brereton and Evans, 1989), while the most suitable for use on core samples are differential strain analysis (Dyke, 1989) and anelastic strain recovery. The effects of scale were comprehensively reviewed by Hyett (1990).

The recently developed technique of anelastic strain recovery may potentially determine directions and magnitudes of principal stresses by measuring changes with time in the geometry of the recovered core. The advantages of this technique are (1) that it does not consume extra drill-ship time and (2) that the measurements are relatively simple. However, a study of stress should include how the results of experimental measurements can be influenced by intrinsic elastic properties and rock characteristics as well as how interpretation may be improved by a knowledge of these properties.

This chapter describes the first attempt to use the anelastic strain recovery technique on cores from the oceanic crust. Site details and summaries of the lithologies encountered during Leg 123 can be found in the Initial Reports volume for Leg 123 and will not be repeated here. Eleven whole-round basalt core samples were collected from Site 765 and another four from Site 766.

\section{ANELASTIC STRAIN RECOVERY}

\section{Background Stress}

Stress is a quantity that cannot be measured directly, but may only be derived by way of its relation with strain or some other indicator. The major group of stress indicators relies on correlation with strain relief mechanisms and associated rock deformation. The release of in-situ stress can generate microcracks through the differential expansion of adjacent grains (Nur and Simmons, 1970). Evidence of cracks generated in this manner for rock samples recovered from deep boreholes has been summarized by Kowallis and Wong (1983). Teufel (1983) argued that these microcracks are aligned primarily by the directions of the principal stresses and that the total microcrack volume from strain recovery is volumetrically proportional to the in-situ stress magnitudes. As a consequence of the development of such a statistically aligned microcrack population, a fully relaxed low-porosity rock might exhibit a microcrack fabric, which may be reflected by corresponding compressional $\left(V_{\mathrm{p}}\right)$ and shear $\left(V_{s}\right)$ wave velocity anisotropies. Teufel (1984) suggested that values of $V_{\mathrm{p}}$ should be least in the direction of maximum strain recovery and greatest in the direction of minimum strain recovery and found evidence to support such a hypothesis. Wolter and Berckhemer (1989) attributed similar observations of velocity anisotropy to the strike of the foliation, but also noted that the principal strain recovery is perpendicular to the foliation.

The strain associated with relaxation of in-situ stored strain energy generally involves both an instantaneous elastic component and a time-dependent anelastic component. Voight (1968) first suggested that empirical justification exists for considering that the partial recoverable component of the anelastic strain will be proportional to the total recoverable strain and, hence, the preexisting state of stress in rheologically isotropic rocks. $\mathrm{He}$ postulated that by measuring rock cores soon after their removal from the borehole, strain and stress ellipsoids calculated from these measurements would enable one to estimate the principal in-situ stress ratios and directions at depth.

Teufel (1982) followed up Voight's propositions by using clip-on disk gauges and found good agreement between stress orientations determined from strain relaxation measurements and those from hydraulic fracture measurements. However, he warned that a strong anisotropy in the rock prior to relief, such as a tectonically induced microcrack fabric, may produce nonlinear creep, which might cause a rotation of the principal axes of strain relief with time and, hence, lead to inaccurate stress orientations.

During anelastic strain recovery monitoring in Devonian shale, Blanton and Teufel (1983) observed contraction of the rocks as well as expansion. They attributed this to large temperature changes in their laboratory at the time and subsequently established temperature-strain correlations with which to correct their field data. However, Teufel (1986) noted that even after temperature corrections had been made, contraction occurred in the minimum horizontal stress direction in all of 18 sandstone cores measured. Strain-recovery core contractions also were noted by Sarda and Perreau (1989) and by Dey and Kranz (1983), who attributed the effect to in-situ pore pressure that caused the diffusion of pore fluid from the sample, deflating the microcracks and competing with the expansion effects.

Wolter and Berckhemer (1989) measured acoustic emission events at the same time they measured anelastic strain recovery and noted a strong correspondence between overall characteristics of both the acoustic emission and the strain recovery curves. They commented that "bursts" of emissions probably reflect avalanchetype microcrack interactions and concluded that although the strain recovery behavior is compatible with a rock behaving as a viscoelastic continuum, the acoustic emission behavior is clear evidence of volumetric expansion by discontinuous tensile microcrack production.

\section{Theoretical Developments}

Voight (1968) postulated that one could determine stress magnitudes and orientations from the proportional expansion of the stress ellipsoid. The orientation of the principal horizontal stresses may be calculated simply from the relative strains measured by each gauge and by considering the geometrical arrangement of the gauges placed around the core (Frocht, 1948; Dally and Riley, 1978; Jaeger and Cook, 1979).

Blanton (1983) developed equations for calculating stress magnitudes on the basis of the assumptions that the rock is linearly viscoelastic, isotropic, and also that the in-situ stresses follow a stepwise unloading function at the moment of coring, which acts as the driving force for the subsequent viscoelastic relaxation. Solutions were obtained for the anelastic recovery of isotropic and transversely isotropic core, in which time-dependent behavior is contained in creep compliance terms. Blanton's equations allow one to calculate the principal stress magnitudes, provided that (1) the principal recovery strains have been measured, (2) Poisson's ratio is known and is constant, and (3) the vertical principal stress can be calculated from the overburden or gravitational loading. The constant Poisson's ratio accommodates a global creep compliance partitioned between distortional and dilatational components.

Blanton and Teufel (1983) further modified these equations by considering the influence of pore pressure. For the isotropic case, the principal horizontal stress magnitudes become,

$$
\begin{aligned}
& \sigma_{x}=\left(\sigma_{z}-\alpha P_{p}\right) \frac{(1-v) \Delta \xi_{x}+v\left(\Delta \xi_{y}+\Delta \xi_{z}\right)}{(1-v) \Delta \xi_{z}+v\left(\Delta \xi_{x}+\Delta \xi_{y}\right)}+\alpha P_{p}, \\
& \sigma_{y}=\left(\sigma_{z}-\alpha P_{p}\right) \frac{(1-v) \Delta \xi_{y}+v\left(\Delta \xi_{x}+\Delta \xi_{z}\right)}{(1-v) \Delta \xi_{z}+v\left(\Delta \xi_{x}+\Delta \xi_{y}\right)}+\alpha P_{p},
\end{aligned}
$$

where

$$
\alpha=1-\frac{K_{b}}{K_{s}},
$$


and also $\sigma_{x}, \sigma_{y}$, and $\sigma_{z}$ are the principal stress magnitudes; $\Delta \xi_{x}$, $\Delta \xi_{y}$, and $\Delta \xi_{z}$ are the changes in principal strains between any two times; $v$ is the isotropic Poisson's ratio; $K_{b}$ and $K_{s}$ are the bulk modulus and matrix material bulk modulus, respectively; and $P_{p}$ is the pore pressure. $\alpha$ is referred to as the poroelastic constant. The $x$ and $y$ suffixes represent the horizontal directions and the $z$ suffix, the vertical direction. When the poroelastic constant is taken to be zero, Equations 1 and 2 revert to Blanton's original equations.

Teufel (1986) conducted a parametric analysis and found that the increase in the minimum horizontal stress, $\sigma_{h}$, was more than six times greater than the corresponding increase in the maximum horizontal stress $\sigma_{H}$ as Poisson's ratio increased from 0.1 to 0.4 . In addition, Poisson's ratio may have a more significant effect on the magnitude of $\sigma_{h}$ than those errors associated with fluctuations in the principal differential strains measured during recovery. Furthermore, $\sigma_{H}$ is not sensitive to changes in the poroelastic constant, but $\sigma_{h}$, significantly decreases with a decrease in $\alpha$. These observations indicate that errors when calculating the principal stress magnitudes from the above equations are more sensitive to errors in the estimation of the mechanical properties of the core, particularly Poisson's ratio, than to errors when measuring in the strain recoveries, and that these errors exert a much stronger influence on the minimum horizontal stress than on the maximum horizontal stress.

Blanton (1989) showed that if $\sigma_{h}$ is known, or can be reliably estimated, then both Poisson's ratio and the pore pressure term can be eliminated from Equations 1 and 2 to permit $\sigma_{H}$ to be determined without the need to know these parameters.

Warpinski and Teufel $(1986,1989 a, 1989 b)$ presented a refined isotropic viscoelastic model that retained some of the assumptions of Blanton's analysis, but was based on curve-fitting the measured anelastic strain recovery data. These equations are of the form,

$$
\begin{aligned}
\xi_{r}(t)= & \left(2 \sigma_{x} \cos ^{2} \theta+2 \sigma_{y} \sin ^{2} \theta-\sigma_{x} \sin ^{2} \theta-\sigma_{y} \cos ^{2} \theta-\sigma_{z}\right) \\
& \left(1-e^{-t h_{1}}\right) J_{1}+\left(\sigma_{x}+\sigma_{y}+\sigma_{z}-3 P_{p}\right)\left(1-e^{-t_{2}}\right) J_{2},
\end{aligned}
$$

and

$$
\begin{aligned}
\xi_{z}(t)= & \left(2 \sigma_{z}-\sigma_{x}-\sigma_{y}\right)\left(1-e^{-v t_{1}}\right) J_{1}+\left(\sigma_{x}+\sigma_{y}+\sigma_{z}-3 P_{p}\right) \\
& \left(1-e^{--n_{2}}\right) J_{2},
\end{aligned}
$$

where $t$ is time; $\theta$ is the gauge angle with respect to the maximum stress orientation; $J_{1}$ and $J_{2}$ are the distortional and dilatational creep compliance arguments, respectively; $t_{1}$ and $t_{2}$ are deviatoric and dilatational creep time constants, respectively; and the suffix $r$ is the radial direction in the horizontal plane. When developing this model, Warpinski and Teufel assumed that strain relaxation takes place through an intergranular fracturing process, the formation of microcracks, or grain boundary sliding, and thus that the matrix material bulk modulus will be neither a viscoelastic parameter, nor need the value of $\alpha$ be specified.

Each of the strain-gauge recovery curves is least-squares fitted to the above model to produce a set of equations relating the principal stress magnitudes to a series of coefficients. Warpinski and Teufel (1989b) noted that the distortional parts of Equations 3 and 4 are the more useful because they do not involve pore pressure. However, these authors found that either the distortional compliance, $J_{1}$, or the minimum horizontal principal stress magnitude, $\sigma_{y}$, is required in addition to the vertical principal stress, $\sigma_{z}$, before the maximum horizontal principal stress can be calculated. The vertical principal stress was calculated in the same way as in the Blanton model by integrating the gravitational loading, but because $J_{1}$ is an unknown or can only be estimated, $\sigma_{y}$ was found by conducting a mini-hydrofracturing stress measurement in tandem with the anelastic strain recovery measurements. Even so, a parametric analysis showed that over a "reasonable range of values," the minimum horizontal stress magnitude was not sensitive to changes in $J_{1}$ and that the maximum horizontal stress was negligibly affected. However, the requirement for independent measures of both the minimum and vertical principal stress magnitudes, before the maximum stress magnitude can be calculated, might represent a serious restriction on the routine use of the Warpinski and Teufel model.

Nevertheless, Warpinski and Teufel (1989b) were able to use their model to reproduce excellent matches with measured strain recovery curves and to reconstruct the entire strain history of a core sample since the time it had been cut. They were also able to do this for siltstone samples from the North Sea that exhibited sustained contractions in all three axes, although they were not able to derive meaningful material properties for these examples. In addition, they were also able to demonstrate the time-dependent response of Poisson's ratio during anelastic strain recovery, emphasizing the need for caution when using the Blanton model.

In a discussion of the Warpinski and Teufel (1989b) study, Blanton (1989) referred to previous work (Blanton and Teufel, 1986) to show that when the two models are presented in a comparable form, they are essentially similar. One exception is that the Warpinski and Teufel model imposes an exponential decay to dilatational creep, whereas the modified Blanton model uses the actual decay, exponential or otherwise. Blanton (1989) claimed somewhat better fits to Warpinski and Teufel's experimental data than they had achieved themselves and also debated the relative merits of some of Warpinski and Teufel's assumptions and criticisms of his model, which provoked a further response from Warpinski and Teufel (1989c).

In a preliminary presentation of anelastic strain recovery results from the German deep drilling project (KTB), Wolter and Berckhemer (1989) invoked a simple exponential decay model (Engelder, 1984) of the form;

$$
\xi_{t}=\xi_{\infty}\left(1-e^{-v}\right)
$$

where $\xi_{t}=$ the strain at any time, $t ; \xi_{\infty}$ is the asymptotic value of strain as time tend to infinity; and the value, $\tau$, is referred to as the relaxation time. By plotting the logarithm of $\xi_{\infty}-\xi_{t}$ vs. $t$, they were able to demonstrate relatively constant relaxation times for much of their data.

\section{Equipment Development and Practical Use}

The underlying basis of the anelastic strain recovery experimental procedure is that upon being released from its in-situ stress environment, a rock core will expand in the direction of and in proportion to the magnitudes of the horizontal and vertical in-situ stresses. The assumption is that the rock sample is homogeneous and will expand elliptically across its section and uniformly along its length. By measuring the physical change in shape of the samples at three or more predetermined positions across its diameter, the orientation and magnitude of the resultant strain recovery ellipsoid can be calculated.

Early attempts to measure anelastic strain recovery (Swolfs, 1975; Strickland and Ren, 1980) used standard rosette-type strain gauges mounted on the surface of the core. Scientists thought that problems associated with this technique led to inconsistent results.

To overcome some of these problems, Teufel (1982, 1983, 1984) used clip-on disk gauges in a temperature-"stabilized" environment and covered the core with polyurethane wrapping to reduce moisture loss. Thereafter, Teufel and Warpinski (1984) 
and Teufel (1986) used spring-loaded clip-on gauges that consisted of a support ring to hold a linear voltage-displacement transducer (LVDT) and an adjustment screw (Holcomb and McNamee, 1984). The support ring and adjustment screw were made from steel alloys chosen for their rigidity and low thermal expansivity. Under this arrangement, the core is horizontally supported at two positions on a frame, and the gauges are mounted across the diameter of the core at two points. The rock core is not restricted in any way, and the LVDT thus is free to respond to any change in diameter of the core without external influence.

A similar approach using LVDTs was adopted by El Rabaa and Meadows (1986) and El Rabaa (1989), except that the core was mounted vertically within a frame that in turn held the LVDTs. Variations on this approach also were adopted by Sarda and Perreau (1989) and Wolter and Berckhemer (1989). However, these methods are open to the criticism that because the core is mounted vertically and the LVDTs are held within a rigid frame, the points of measurement will be subjected to lateral forces as the core undergoes anelastic strain recovery along its length.

To overcome the effects of evaporation of the core fluids and also to stabilize the temperature of the rock core and the measuring equipment, Sarda and Perreau (1989) placed the core and equipment in an oil bath, while Wolter and Berckhemer (1989) coated the core with wax. In each case, the core and measuring gauges were placed in a temperature-stabilized environment.

Principal stress orientations usually are calculated with respect to a scribe line marked along the length of a core. The core, in turn, must be oriented with respect to magnetic North. Ideally, this should be performed with an orientation device built into the core barrel (Teufel, 1986), but it can be done from the borehole televiewer of formation microscanner images from logs subsequently run in the borehole (Wolter and Berckhemer, 1989).

BP Research (Sunbury) U.K. followed the Holcomb and McNamee philosophy, but with modifications to equipment details and measuring techniques. The BP equipment was made available to the British Geological Survey (BGS) during the early stages of this project, and many of their design features were incorporated into the equipment used during Leg 123.

The essentials of the BGS equipment (Fig. 1) are as follows:

1. An adjustable frame holds a core sample horizontal.

2. A set of four LVDT strain transducers is mounted within carbon-fibre support rings. Carbon fibre was chosen because of its high stiffness, low weight, and low coefficient of thermal expansion relative to steel. The strain-gauging transducers have a range of $\pm 2 \mathrm{~mm}$, a limit of measurement sensitivity of less than $0.1 \mu \mathrm{m}$, a linearity of $0.25 \%$ of range, and a temperature coefficient of $0.01 \% /{ }^{\circ} \mathrm{C}$. The strain transducers are fitted with $60^{\circ}$ conical tips and springs of just sufficient strength to support the weight of the ring assembly. Adjustable and lockable support bars, diametrically opposite the LVDT, are made from Invar steel alloy having a low thermal coefficient of expansion. The core longitudinal-axis strain-transducer support is made from carbonfibre rods and alloy bars.

3. The effects of any slight temperature variation on the support-ring/strain-transducer/ adjustment-bar assembly are monitored by a sixth strain-transducer set across a glass ceramic disk having a low coefficient of thermal expansion $\left(0.05 \times 10^{-6} /{ }^{\circ} \mathrm{C}\right.$ over a $0^{\circ}-50^{\circ} \mathrm{C}$ temperature range). Any apparent strain changes recorded across the disk are taken to reflect temperature and other environmental effects on the equipment itself and are subsequently subtracted from the recorded output of each of the core-measurement gauges.

4. A platinum temperature probe is used to record the temperature immediately adjacent to the core sample.
5. The rock sample is placed on the frame, together with the strain gauging transducers and temperature sensor, inside a thermally insulated container filled with an inert silicon fluid. The high thermal inertia of the silicon fluid together with the thermally insulated container serve to minimize the effects of laboratory temperature fluctuations and also to prevent loss of pore fluid from the core by evaporation. In addition, a sufficiently high fluid viscosity is chosen to dampen out potential vibrations transmitted from the ship to the sensitive strain transducers.

6. The strain-transducer and temperature-sensor control unit is interfaced with a portable microcomputer that acts as a data logger. The data are captured directly into a spreadsheet using Lotus Measure as the communication software.

Up to three rock cores can be monitored at a time, and the equipment can be set to collect and record data at intervals of from $1 \mathrm{~min}$ for a period of up to several days without attendance. At any time during data collection, a realtime graphical display allows for monitoring of progress and data quality.

A tee-delta strain-transducer arrangement (Dalley and Riley, 1978 ) is used, whereby the four gauges are positioned at $0^{\circ}, 60^{\circ}$, $90^{\circ}$ and $120^{\circ}$ around the core, referred to as positions A, B, D, and $C$, respectively. Position $A$ is arranged to correspond with the scribe line. The use of four gauges, rather than three, effectively gives more data than necessary and thus greater confidence in the results.

The principal horizontal strains and their orientations are calculated from the following relationships:

$$
\xi_{H, h}=\frac{\xi_{A}+\xi_{D}}{2} \pm \frac{1}{2} \sqrt{\left(\xi_{A}-\xi_{D}\right)^{2}+\frac{4}{3}\left(\xi_{C}-\xi_{B}\right)^{2}},
$$

and

$$
\tan 2 \varphi_{H}=\frac{2\left(\xi_{C}-\xi_{B}\right)}{\sqrt{3}\left(\xi_{A}-\xi_{D}\right)},
$$

where, $\xi_{A, B, C, D}$ are the strain recoveries measured by the respective LVDTs, $\xi_{H, h}$ are the maximum and minimum principal horizontal strains, respectively, and $\phi_{H}$, is the negative angle of $\xi_{H}$ (following the sign convention adopted by Dally and Riley, 1978) from measurement position $\mathrm{A}$.

Equations 6 and 7 assume an idealized elliptical deformation of the rock. Yasunaga (1989) showed that this hypothesis can be tested with the following relationship:

$$
\xi_{A}-2\left(\xi_{B}+\xi_{C}\right)+3 \xi_{D}=0
$$

The nearer the left side of Equation 8 is to zero, the nearer the rock deformation approximates an ellipse.

\section{Leg 123 Shipboard Measurements}

\section{Sample Selection and Preparation}

None of the sediment cores recovered from Holes 765A, 765B, and $765 \mathrm{C}$ were sufficiently lithified to be suitable for anelastic strain recovery experiments. The first sample for this study was thus taken from the first complete basement core at Hole $765 \mathrm{C}$ (Bas 1). The subsequent poor recovery of concomitant wholeround rock core resulted in only 10 additional samples being recovered from Hole $765 \mathrm{D}$ before drilling ceased. In most cases, the overall core was so broken that the samples that were recov- 

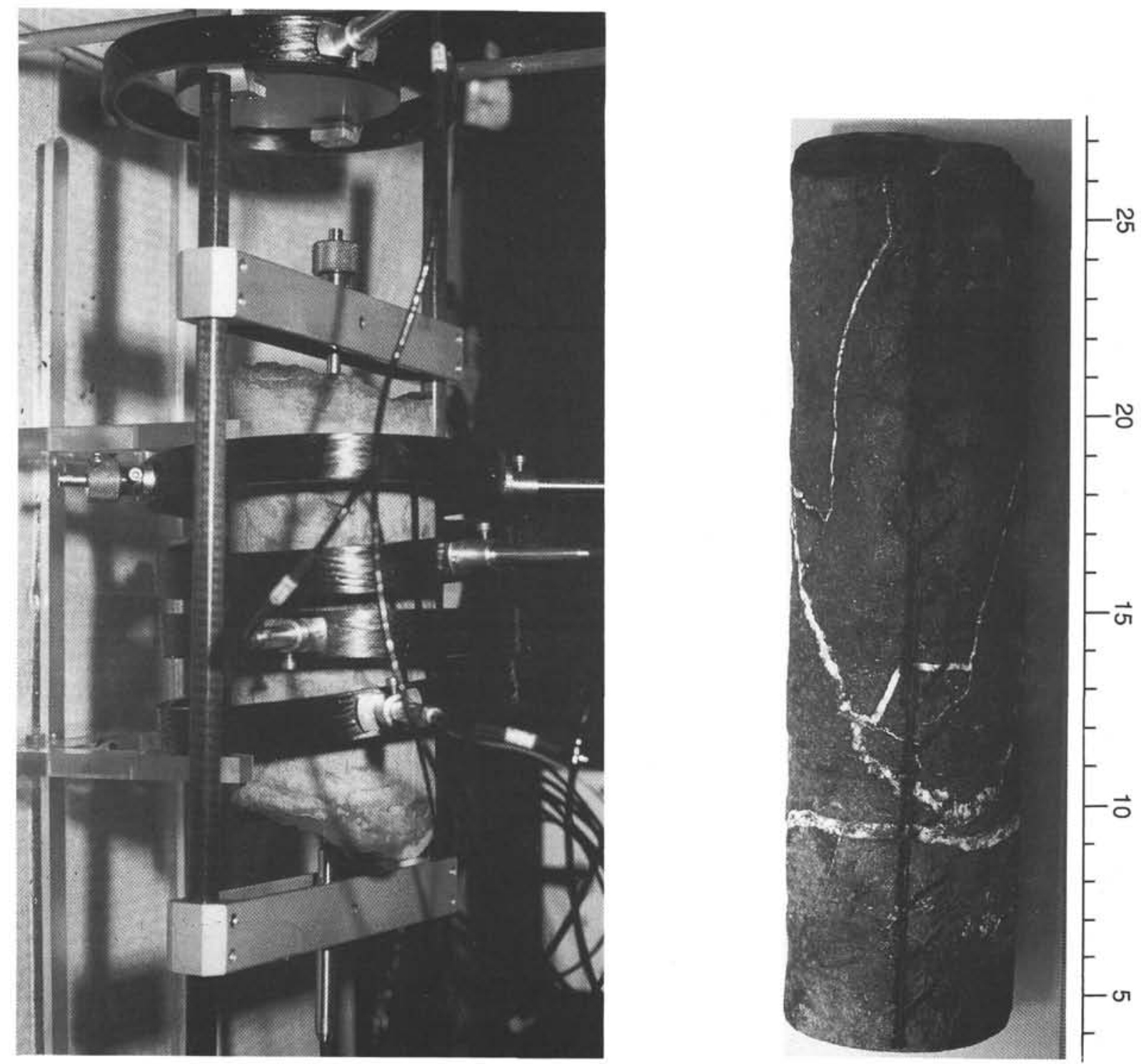

Figure 1. Anelastic strain recovery equipment and core sample Bas 1. 
ered were the only suitable ones available. Similarly, none of the sediment cores recovered from Hole $766 \mathrm{~A}$ were suitable for anelastic strain recovery experiments. The diabase dolerite samples from Site 766 were less invaded by calcite veins than those from Site 765 and were selected for being as free as possible from such features. The last two samples (Bas 14 and Bas 15) were recovered from the same core section and were immediately adjacent to one another. The break in the rock between these two samples could be matched, so that one continuous scribe line could be drawn from one to the other. This permitted reproducibility of the results for assessment between two halves of what is essentially one sample.

An outline of the sample preparation is presented in the Initial Reports volume of Leg 123 and in a more detail by Brereton et al. (1990) and will not be repeated here.

\section{Results}

The equipment for measuring stress recovery of the core performed without fault, and the silicon fluid prevented any drying out of the sample during measurement periods. The thermal insulation afforded by the immersion of the sample within the silicon fluid inside the insulated container restricted the temperature drift during the experimental periods to a maximum of $0.8^{\circ} \mathrm{C}$, but generally to within $0.3^{\circ} \mathrm{C}$.

We have been unable to conduct a full parametric analysis of the errors in the calculated maximum and minimum strain recoveries and in strain recovery angles that can be directly attributed to equipment measurement errors, and clearly, this will depend upon the magnitude of the recovered strains, but we think these errors are small in relation to the geological and geomechanical factors.

The displacements recorded by each of the gauging transducers were converted into strains, and the maximum and minimum principal horizontal strains and the angle of the maximum principal horizontal strain relative to the scribe line, $\phi_{H}$ (a negative angle, following the sign convention adopted by Dally and Riley, 1978), were calculated from Equations 6 and 7. The values of $\phi_{H}$. and $\xi_{H, h, V}($ shown in Tables 1 and 2) were taken as the means over the final few hours of strain recovery when approximate equilibrium had been achieved.

No core orientation device was used when drilling during Leg 123 , and thus the orientation of the stress ellipsoid relative to magnetic North was determined from paleomagnetic measurements. Shipboard scientists also hoped to use the borehole televiewer to help orient the samples, but the quality of the televiewer output during the cruise was not good enough. The relative position of magnetic North during the Early Cretaceous for the western Australian margin has been estimated as $270^{\circ} \pm 30^{\circ}$ (Embleton, 1981, 1984). If the mean magnetic orientation with respect to the scribe line is $\theta$ (Table 1 ), then the position of the scribe line relative to present-day North is $270-\theta$, and the orientation of the maximum principal horizontal strain relative to present-day North $\left(\Delta_{H}\right)$ is $270-\theta-\phi_{H}$. These orientations are shown in Table 1.

As discussed earlier, instrumental errors when determining the strain recovery orientations are thought to be small. Deviations about the mean are shown in Table 1 and are generally less than $2^{\circ}$. The instrumental error in the paleomagnetic measurements is estimated as $\pm 5^{\circ}$ (James Ogg, pers. comm., 1988), and the systematic error in the position of North during the Early Cretaceous is $\pm 30^{\circ}$. However, as mentioned in the previous section, the last two samples (Bas 14 and Bas 15) were recovered from the same core section immediately adjacent to one another and can be regarded as duplicates. The angles of maximum strain relief, relative to the scribe line marked onto these two samples, were $20^{\circ}$ apart, while the angles of paleomagnetic measurements were $41^{\circ}$ apart. Therefore, the total error in $\Delta_{H}$, including both instru- mental errors and "geological" errors, is difficult to estimate, but may be significant.

In an initial appraisal of the Leg 123 strain recovery data, Yasunaga (1989) used Equation 8 to estimate how closely the recorded core sample deformations approximated an ellipse. He found that values for the left side of the equation were 0.2 for core Bas $11 ; 22$ for Bas 5 ; between \pm 40 and 81 for Bas $1,3,6,7,10$, 13 , and 15; and between \pm 121 and 205 for Bas $2,4,8,9,12$, and 14. The implication from these results is that for many of the core samples, the four horizontal gauge recordings are not representative of elliptical deformation. However, the application of this check should be more rigorously validated before it can be used quantitatively.

The vertical and maximum and minimum principal horizontal strains are shown in Table 2. Also shown are the elapse times from the onset of strain relief monitoring to approximate equilibrium. The graphical results of the principal strain recovery curves, the LVDT measured strain recovery curves, the principal angles, $\phi_{H}$. and the recorded temperatures for each core sample have been described by Brereton et al. (1990), but examples for the samples Bas 4, 8, 9, and 12 are shown in Figure 2. Uncorrected preliminary principal-strain recovery curves for the samples Bas 1,2 , and 8 were shown in the Initial Reports volume of Leg 123.

Only the core samples Bas 7 and 11 exhibit the classical anelastic strain recovery expansion curves in all three axes, while Bas 5 and 9 exhibit similar initial trends that then reverse to become contractions in the minimum horizontal or vertical axes. The core samples Bas 1, 2, 6, 8, and 10 mainly show smooth, relatively large-magnitude expansions in the maximum horizontal and vertical axes and contractions in the minimum horizontal axis. For all but one of these samples (Bas 1), the minimum horizontal axis contractions were derived from the response of only one of the five LVDTs, with the other four recording expansions. The samples Bas 13,14, and 15 exhibit consistently smooth, relatively large contractions in the vertical axes, while Bas 13 and 14 contracted in the maximum and minimum horizontal axes as well. All the LVDT responses for the sample Bas 12 (Fig. 2D) were contractions for the first $2 \mathrm{hr}$, but thereafter one of the horizontal and the vertical measuring LVDTs changed to record relatively large-magnitude expansions. Bas 3 was subject to disturbance in the laboratory, and thus these results are best ignored.

The most startling result is from sample Bas 4 (Fig. 2A) from $1005.78 \mathrm{mbsf}$ at Site 765 , where the strain relief was large and consistently negative in all three directions and continued to recover for almost $80 \mathrm{hr}$ without showing signs of reaching equilibrium. A similar result has since been reported by Warpinski and Teufel (1989b), where a North Sea siltstone contracted consistently in all three axes for almost $40 \mathrm{hr}$.

The relaxation time analysis (Eq. 5) described by Wolter and Berckhemer (1989) was applied to the derived principal strain curves. In general, we found that most of the core samples exhibited some degree of linearity on the semi-log plots, but this was usually over fairly limited time ranges and also over those portions of the displacement-time curves that "looked" exponential. Only Bas 2 exhibited consistent linearity over most of the time range for all three axes, while the Bas 4 plots showed consistent curvature. No apparent correlation or trend among the derived relaxation times, either for each core sample or between core samples, was observed.

\section{Thermal Stabilization of Core Samples}

We recognized from the outset that thermal stabilization of the core samples might be an imponderable. The temperature at 1195 mbsf in Hole $765 \mathrm{D}$ was $38.9^{\circ} \mathrm{C}$ (Ludden, Gradstein, et al., 1990). During the coring process, the core barrel was flushed with drilling fluid and was subsequently hauled up through almost 
Table 1. Principal strain orientations derived from paleomagnetic and anelastic strain recovery angles.

\begin{tabular}{|c|c|c|c|c|}
\hline Sample & $\begin{array}{l}\text { Depth } \\
\text { (mbsf) }\end{array}$ & $\begin{array}{c}\text { Paleomagnetic } \\
\text { angle } \\
(\theta)\end{array}$ & $\begin{array}{c}\text { Anelastic recovery } \\
\text { angle } \\
\left(\phi_{H}\right)\end{array}$ & $\begin{array}{c}\text { Strain } \\
\text { orientation } \\
\left(\Delta_{H}\right)^{\mathrm{a}}\end{array}$ \\
\hline \multicolumn{5}{|l|}{ Site 765} \\
\hline $\begin{array}{c}\text { Bas 1 } \\
765 \mathrm{C}-63 \mathrm{R}-2 \text {, } \\
34-54 \\
\text { Bas 2 }\end{array}$ & 937.58 & 219 & $-67.3 \pm 0.3$ & 118 \\
\hline $\begin{array}{c}765 \mathrm{D}-3 \mathrm{R}-1 \\
110-125 \\
\text { Bas } 3\end{array}$ & 965.47 & 23 & $29.2 \pm 0.2$ & 38 \\
\hline $\begin{array}{c}\text { 765D-5R-6, } \\
110-129 \\
\text { Bas } 4\end{array}$ & 990.76 & 320 & $85.7 \pm 4.5$ & 44 \\
\hline $\begin{array}{c}765 \mathrm{D}-7 \mathrm{R}-3 \\
90-110 \\
\text { Bas } 5\end{array}$ & 1005.78 & -54 & $-38.7 \pm 0.2$ & 3 \\
\hline $\begin{array}{c}765 \mathrm{D}-13 \mathrm{R}-1, \\
31-50 \\
\text { Bas } 6\end{array}$ & 1054.71 & 87 & $-20.1 \pm 0.7$ & 23 \\
\hline $\begin{array}{c}\text { 765D-18R-3, } \\
37-54 \\
\text { Bas } 7\end{array}$ & 1103.51 & 260 & $8.2 \pm 0.9$ & 2 \\
\hline $\begin{array}{c}765 \mathrm{D}-19 \mathrm{R}-2, \\
0-27 \\
\text { Bas } 8\end{array}$ & 1111.60 & 166 & $-2.6 \pm 2.2$ & 107 \\
\hline $\begin{array}{c}\text { 765D-20R-1, } \\
77-99 \\
\text { Bas } 9\end{array}$ & 120.27 & 211 & $-11.7 \pm 0.1$ & 71 \\
\hline $\begin{array}{c}\text { 765D-22R-2, } \\
0-16 \\
\text { Bas } 10\end{array}$ & 1138.60 & 354 & $36.5 \pm 0.2$ & 59 \\
\hline $\begin{array}{c}\text { 765D-24R-5, } \\
73-90 \\
\text { Bas } 11\end{array}$ & 1163.09 & 350 & $-12.5 \pm 0.4$ & 113 \\
\hline $\begin{array}{c}\text { 765D-26R-1, } \\
73-92\end{array}$ & 176.73 & 293 & $82.8 \pm 1.3$ & 74 \\
\hline \multicolumn{5}{|l|}{ Site 766} \\
\hline $\begin{array}{c}\text { Bas } 12 \\
766 \text { A-51R-5, } \\
93-114 \\
\text { Bas } 13\end{array}$ & 487.14 & 45 & $2.7 \pm 0.1$ & 42 \\
\hline $\begin{array}{c}766 \mathrm{~A}-52 \mathrm{R}-2 \\
131-147 \\
\text { Bas } 14\end{array}$ & 492.72 & 289 & $88.0 \pm 1.2$ & 73 \\
\hline $\begin{array}{c}766 \mathrm{~A}-55 \mathrm{R}-6 \\
33-57 \\
\text { Bas } 15\end{array}$ & 524.56 & 286 & $-58.9 \pm 3.0$ & 43 \\
\hline $\begin{array}{c}766 \mathrm{~A}-55 \mathrm{R}-6 \\
57-76\end{array}$ & 524.80 & 327 & $-79.1 \pm 1.0$ & 22 \\
\hline
\end{tabular}

${ }^{\mathrm{a}} \Delta_{H}=270-\theta-\phi_{H}$.

$6 \mathrm{~km}$ of ocean water, thereby cooling the rock core to about $4^{\circ} \mathrm{C}$ for several hours. The average temperature of the silicon fluid within which the sample was immersed in the shipboard laboratory was about $26^{\circ} \mathrm{C}$. Therefore, the core samples, over the space of a few hours, were subjected to thermal cycling that imposed an indeterminate temperature profiled through the rock. How long the cores then took to reach equilibrium with the silicon fluid depended upon the thermal characteristics of the basalt.

An examination of the temperature curves and some of the LVDT responses indicated that core samples had retained a proportion of their in-situ heat, but that during the first hour or so, the cores had became sufficiently thermally stabilized so that the effects of temperature thereafter were negligible (Brereton et al., 1990).

This conclusion was confirmed by subjecting three core samples (Bas 4, 8, and 12) to a heating-cooling cycle designed to replicate their experiences following coring. This experiment was conducted some months later, when the samples had fully relaxed from the effects of in-situ stresses and any surface moisture had evaporated. The results from this thermal cycling showed that while the strain recovery curves may be influenced by thermal stabilization processes taking place during the first $2 \mathrm{hr}$, thereafter these processes can be discounted.

\section{Thermal Azimuthal Anisotropy}

It became clear during equipment construction and testing that not only was there a strong correlation between core sample deformation and temperature, but that thermal expansion-contraction invariably exhibited strong azimuthal anisotropy. Charlez et al. (1986) debated whether microcracking of a rock is a memory of its initial state of stress, while Lacy (1987) conducted both anelastic strain recovery and thermal expansion testing and re- 
Table 2. Anelastic strain recovery principal strains.

\begin{tabular}{|c|c|c|c|c|c|}
\hline \multirow[b]{2}{*}{ Sample } & \multirow[b]{2}{*}{$\begin{array}{l}\text { Depth } \\
\text { (mbsf) }\end{array}$} & \multicolumn{3}{|c|}{ Final principal strains } & \multirow[b]{2}{*}{$\begin{array}{l}\text { Elapse } \\
\text { time }^{a}\end{array}$} \\
\hline & & $\begin{array}{c}\xi_{H} \\
\text { (m strains) }\end{array}$ & $\begin{array}{c}\xi_{h} \\
\text { (m strains) }\end{array}$ & $\frac{\xi_{V}}{\text { (m strains) }}$ & \\
\hline \multicolumn{6}{|l|}{ Site 765} \\
\hline $\begin{array}{c}765 C-63 R-2, \\
34-54 \\
\text { Bas } 2\end{array}$ & 937.58 & $31.5 \pm 0.7$ & $-47.6 \pm 0.9$ & $1.1 \pm 0.8$ & 38.6 \\
\hline $\begin{array}{c}\text { 765D-3R-1, } \\
110-125 \\
\text { Bas } 3\end{array}$ & 965.47 & $46.3 \pm 0.6$ & $-41.1 \pm 0.9$ & $57.9 \pm 0.6$ & 22.5 \\
\hline $\begin{array}{c}\text { 765D-5R-6, } \\
110-129 \\
\text { Bas } 4\end{array}$ & 990.76 & $-2.1 \pm 0.7$ & $-6.7 \pm 0.9$ & $5.9 \pm 0.4$ & 11.6 \\
\hline $\begin{array}{c}765 \mathrm{D}-7 \mathrm{R}-3, \\
90-110 \\
\text { Bas } 5\end{array}$ & 1005.78 & $-70.5 \pm 0.5$ & $-205.9 \pm 0.6$ & $-102.9 \pm 0.3$ & 79.5 \\
\hline $\begin{array}{c}\text { 765D-13R-1, } \\
31-50 \\
\text { Bas } 6\end{array}$ & 1054.71 & $49.7 \pm 0.6$ & $5.6 \pm 1.1$ & $1.5 \pm 0.2$ & 25.0 \\
\hline $\begin{array}{c}\text { 765D-18R-3, } \\
37-54 \\
\text { Bas } 7\end{array}$ & 1103.51 & $5.0 \pm 0.6$ & $-24.9 \pm 0.5$ & $14.1 \pm 0.4$ & 11.5 \\
\hline $\begin{array}{c}\text { 765D-19R-2, } \\
0-27 \\
\text { Bas } 8\end{array}$ & 1111.60 & $14.5 \pm 0.8$ & $2.5 \pm 0.8$ & $6.6 \pm 0.2$ & 5.7 \\
\hline $\begin{array}{c}\text { 765D-20R-1, } \\
77-99 \\
\text { Bas } 9\end{array}$ & 1120.27 & $139.0 \pm 0.8$ & $-3 \pm 0.4$ & $28.5 \pm 0.2$ & 46.3 \\
\hline $\begin{array}{c}\text { 765D-22R-2, } \\
0-16 \\
\text { Bas } 10\end{array}$ & 138.60 & $81.9 \pm 0.8$ & $6.1 \pm 0.7$ & $21.4 \pm 0.3$ & 20.1 \\
\hline $\begin{array}{c}\text { 765D-24R-5, } \\
73-90 \\
\text { Bas } 11\end{array}$ & 1163.09 & $20.2 \pm 0.7$ & $-9.9 \pm 0.6$ & $18.3 \pm 0.1$ & 19.9 \\
\hline $\begin{array}{c}765 \mathrm{D}-26 \mathrm{R}-1, \\
73-92\end{array}$ & 1176.73 & $25.5 \pm 0.9$ & $12.6 \pm 1.0$ & $16.1 \pm 0.4$ & 9.9 \\
\hline \multicolumn{6}{|l|}{ Site 766} \\
\hline $\begin{array}{c}\text { Bas } 12 \\
\text { 766A-51R-5, } \\
93-114 \\
\text { Bas 13 }\end{array}$ & 487.14 & $144.8 \pm 1.2$ & $-51.3 \pm 0.7$ & $-5.6 \pm 0.2$ & 19.7 \\
\hline $\begin{array}{c}766 \mathrm{~A}-52 \mathrm{R}-2, \\
131-147 \\
\text { Bas } 14\end{array}$ & 492.72 & $2.0 \pm 1.2$ & $-12.5 \pm 0.9$ & $-36.5 \pm 0.3$ & 14.8 \\
\hline $\begin{array}{c}\text { 766A-55R-6, } \\
33-57 \\
\text { Bas } 15\end{array}$ & 524.56 & $-24.6 \pm 1.3$ & $-41.6 \pm 1.6$ & $-30.3 \pm 0.3$ & 19.5 \\
\hline $\begin{array}{c}766 \mathrm{~A}-55 \mathrm{R}-6, \\
57-76\end{array}$ & 524.80 & $11.8 \pm 1.7$ & $-3.1 \pm 1.3$ & $-33.4 \pm 0.2$ & 19.5 \\
\hline
\end{tabular}

${ }^{a}$ Hours from onset of strain relief monitoring.

ported that the results from the same cores were usually consistent.

The core samples, Bas 4,8 , and 12 , were instrumented as if strain recovery was to be recorded, but were placed on the BGS laboratory bench and allowed to respond to air temperature changes cycling up and down between $15.5^{\circ}$ and $26.5^{\circ} \mathrm{C}$ over several days. First, an obvious and marked correlation was seen between apparent strain and temperature, but a considerable degree of anisotropic behavior also was noted. The displacementtemperature curves ranged from being virtually linear with a high correlation coefficient and little or no hysteresis through exhibiting hysteresis by following different displacement curves, depending on whether the temperature was increasing or decreasing, to exhibiting an incoherent response with little correlation at all. Some of the gauges across both Bas 8 and Bas 12 showed consistently negative slopes to the curves. The maximum slopes for Bas 4,8 , and 12 , respectively, were 19,21 , and 26 , microstrains $/{ }^{\circ} \mathrm{C}$, while the minimum slopes were $7,-5$ and -7 microstrains $/{ }^{\circ} \mathrm{C}$. The responses of the strain gauge assemblies mounted over the glass ceramic disks were generally somewhat erratic with a low correlation coefficient and a maximum of no more than 6 microstrains $/{ }^{\circ} \mathrm{C}$ for short periods of time. The orientations of maximum thermal expansion showed a tendency to switch through $90^{\circ}$, depending upon changes in the relative magnitudes of measured strains with temperature for individual LVDTs. However, apart from Bas 4, no apparent consistency existed between the thermal expansion orientations and the strain recovery orientations.

\section{INTERPRETATIVE STRATEGY}

One can clearly see from previous sections that the strain recovery curves, obtained on board the ship, exhibited large variations, both in the character of the relaxation curves and in the calculated directions of the principal horizontal stresses. Most curves show expansion, as expected, but also contractions, while 
the orientations of maximum compressive stress showed no consistent trend (Table 1). Factors that can explain these potential variations are grouped under the following topics:

1. Instrumental problems.

2. Core orientation inaccuracies.

3. Complex in-situ stress conditions.

4. Anisotropy of elastic properties in the basalt samples.

In general, we considered instrument errors were small and negligible in comparison to the magnitudes of the strains recorded. Concerning core-orientation errors, we have not, as yet, been able to check out more rigorously the paleomagnetic results, but any error in the estimation of the pole direction during the Early Cretaceous, of course, will be systematic and common to all the results and thus cannot account for variations among the orientations of core samples.

The possibility of complex stress conditions in the in-situ rock mass (perhaps involving significant localized pore-water pressure variations and macro anisotropic characteristics that invalidate some of the theoretical assumptions) remains. The problem of elastic anisotropy is potentially of major importance, because the assumption of isotropy is fundamental to the anelastic strain recovery method. Therefore, information about the elastic properties or factors that influence elastic properties should be considered. These properties are also important for providing clues to the mechanisms of strain recovery.

The elastic properties of the sample will be controlled by a variety of factors, including visible fractures and voids on a macro-scale, and mineralogy, crystal orientation, and cracks on a micro-scale. Information was sought by a variety of methods, including the following:

1. Macrocrack characterization (with bulk sample description).

2. Mineralogy (from thin section analysis).

3. Scanning electron microscopy.

4. Dynamic measurements of seismic velocities.

Not all of the recovered basalt samples for which anelastic strain recovery measurements were recorded could be studied in detail, and some selectivity was necessary.

\section{CHARACTERIZATION OF CORE SAMPLES}

\section{Macro-Characterization Study}

It was clear from a superficial examination that core samples were intersected by an abundance of fractures, some of which passed right through the samples and were cemented by calcite or other minerals. Therefore, before any destructive work was done on the cores, we considered it prudent to construct a qualitative description of the fracture structure of each core.

It is difficult to express three-dimensional structures in two dimensions, and various attempts to accomplish this included the following:

1. Photographing at $90^{\circ}$ intervals around the core.

2. Photographing with vertical and horizontally polarized light.

3. Photographing with ultraviolet and fluorescent dye.

4. X-ray photography.

5. Surface tracing and feature moulding.

All samples were photographed at $90^{\circ}$ intervals as a general record, but we concluded that none of the above methods improved upon the visual tracing by hand on transparent sheeting as a means of recording small but visible cracks. Tracings for each of the cores have been described by Brereton et al. (1990), but examples for the samples Bas 4, 8, 9, and 12 are shown in Figure 3. In each case, the angular orientation around the core is related to the scribe line.

A persistent fracture plane through a core is characterized, on a two-dimensional representation, by a sine curve. Evidence of such sine curves was clear (Bas 12), but most of the fracturing is more complex. Most of the cores exhibit a considerable number of fractures, some intensely so (Bas 8). Only the cores Bas 12, 14, and 15 from Site 766 are relatively free of fractures. Some fractures have been intercepted by others, and some terminate within the rock matrix. Some are smoothly curved, while others are angular and rough. Many are filled and cemented. Two general observations about fracture structures can be made: (1) the persistency of the fractures is relatively small so that most terminate in the core, either by interception or by disappearing into the rock matrix; and (2) four dominant fracture sets seem to be suggested as being almost vertical or almost horizontal and have dips of about $60^{\circ}$ and $40^{\circ}$.

Core structures also were traced on board the Resolution by the USGS-Stanford team (Ludden, Gradstein, et al., 1990). These scientists recorded a population of fractures from 27 cores from Site 765 that were generally symmetrically oriented, some of which were filled with calcite, smectite, and other clay alteration minerals. The dominant dip angle of through-going fractures fell near $45^{\circ}$, with additional nodes near $30^{\circ}$ and $60^{\circ}$, but the range covered from $15^{\circ}$ to $90^{\circ}$. A similar study was conducted using seven cores from Site 766. Again, the dominant dip angle fell near $45^{\circ}$, with a range of from $5^{\circ}$ to $80^{\circ}$, but no clearly defined additional nodes. Most of these fractures were filled with smectite and minor amounts of pyrite. Secondary crack growth was often associated with a trend that cross-cut the preexisting fractures at oblique angles. These late-forming fractures were often, though not always, filled with calcite. An interesting feature of the basalt cores at Site 766 was a systematic increase in dip angle from clustering near $45^{\circ}$ above about $505 \mathrm{mbsf}$, to growing progressively steeper to about $80^{\circ}$ by $515 \mathrm{mbsf}$, and then decreasing again to about $20^{\circ}$ below about $520 \mathrm{mbsf}$. This change in dip angle was considered to result from thermoelastic stresses that occurred within the cooling body of the intrusive basalt, coupled with the tectonic stresses prevalent at the time of intrusion.

Many of the fractures that split the cores from Site 766 into smaller pieces showed the morphological features of core disking described by Dyke (1989) and by Sarda and Perreau (1989).

\section{Micro-Characterization Study}

Thin sections were made from subcores drilled from samples Bas $1,4,8,11,12$, and 15 to ascertain the nature of the crack fillings and to see if any mineral orientation or banding might have contributed to elastic property anisotropy. The pyroxene/plagioclase crystals showed no apparent orientation, nor was there any obvious flow structure or banding on this scale. Most cracks are filled with calcite, but others contain green clay minerals or opaque minerals. Relict vesicles are present, usually filled with calcite. Although the thin sections showed some cracks (which cannot be seen without the microscope), they do not provide any more evidence of crack orientation than could be seen with the naked eye on the hand specimens.

In addition to the optical study, pore structure was examined using scanning electron microscopy (SEM). A slice from each of the thin-sectioned cores was taken using a slow-cutting saw to minimize crack damage and then polished with a $1 \mu \mathrm{m}$ paste.

The observations from the thin section and the SEM studies showed that, in general, the cracks could be categorized as follows: 

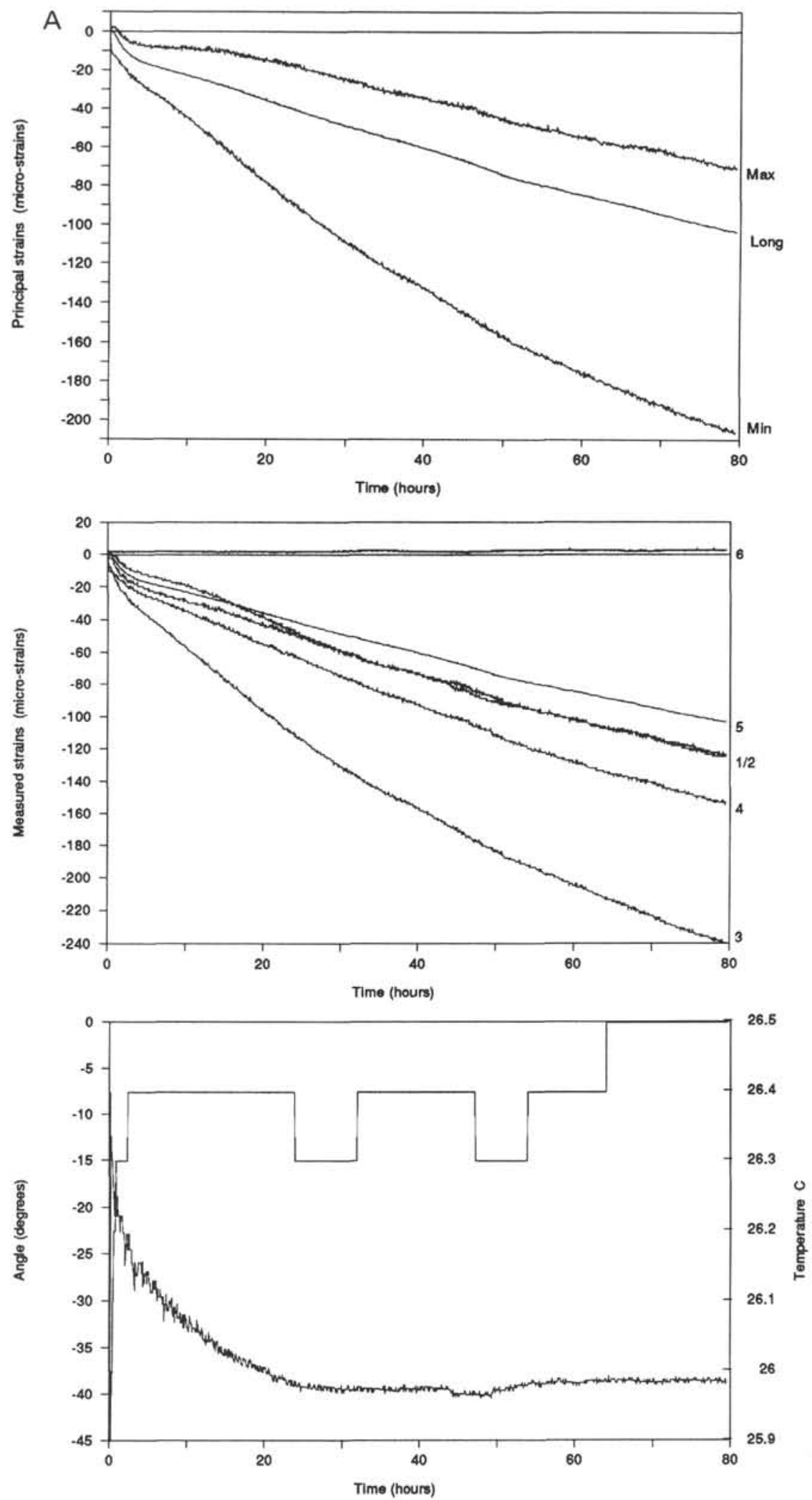

Figure 2. Graphical results from the anelastic strain recovery measurements. Examples for core samples Bas 4 (A), 8 (B), 9 (C), and 12 (D) are shown with three diagrams for each: (1) the calculated principal strains showing the maximum and minimum horizontal strains and the vertical or longitudinal strain; (2) the LVDT-measured strains where numbers 1,2,3, and 4 correspond to $\mathbf{A}, \mathbf{B}, \mathbf{C}$, and $\mathbf{D}$ around the core; $5=$ the vertical measurement; $6=$ the response from the glass ceramic disk; (3) the calculated angle of the maximum strain direction relative to the scribe line marked on the core sample and the temperature recorded immediately adjacent to the core during the course of the measurements. 

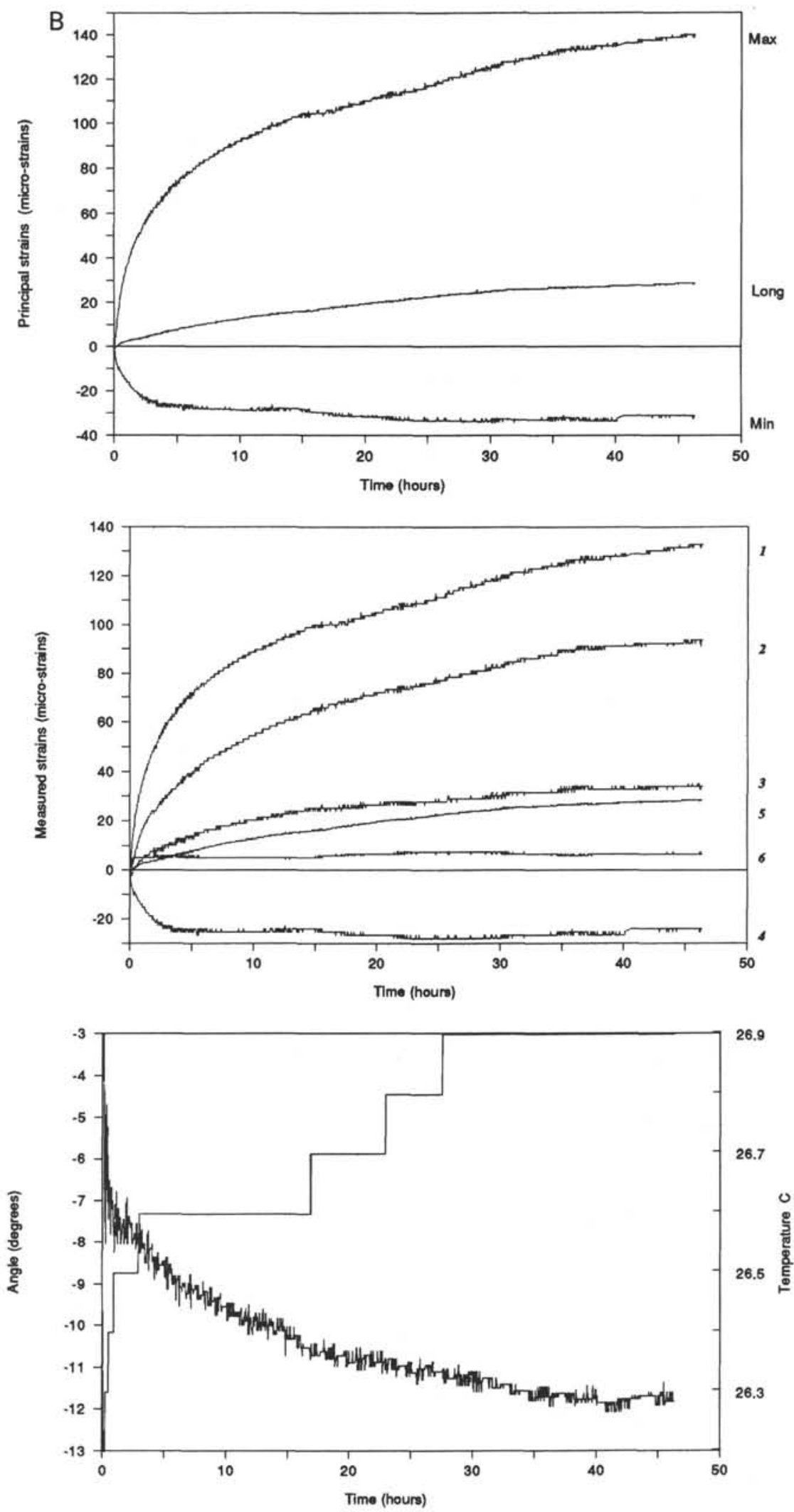

Figure 2 (continued). 
N. R. BRERETON ET AL.
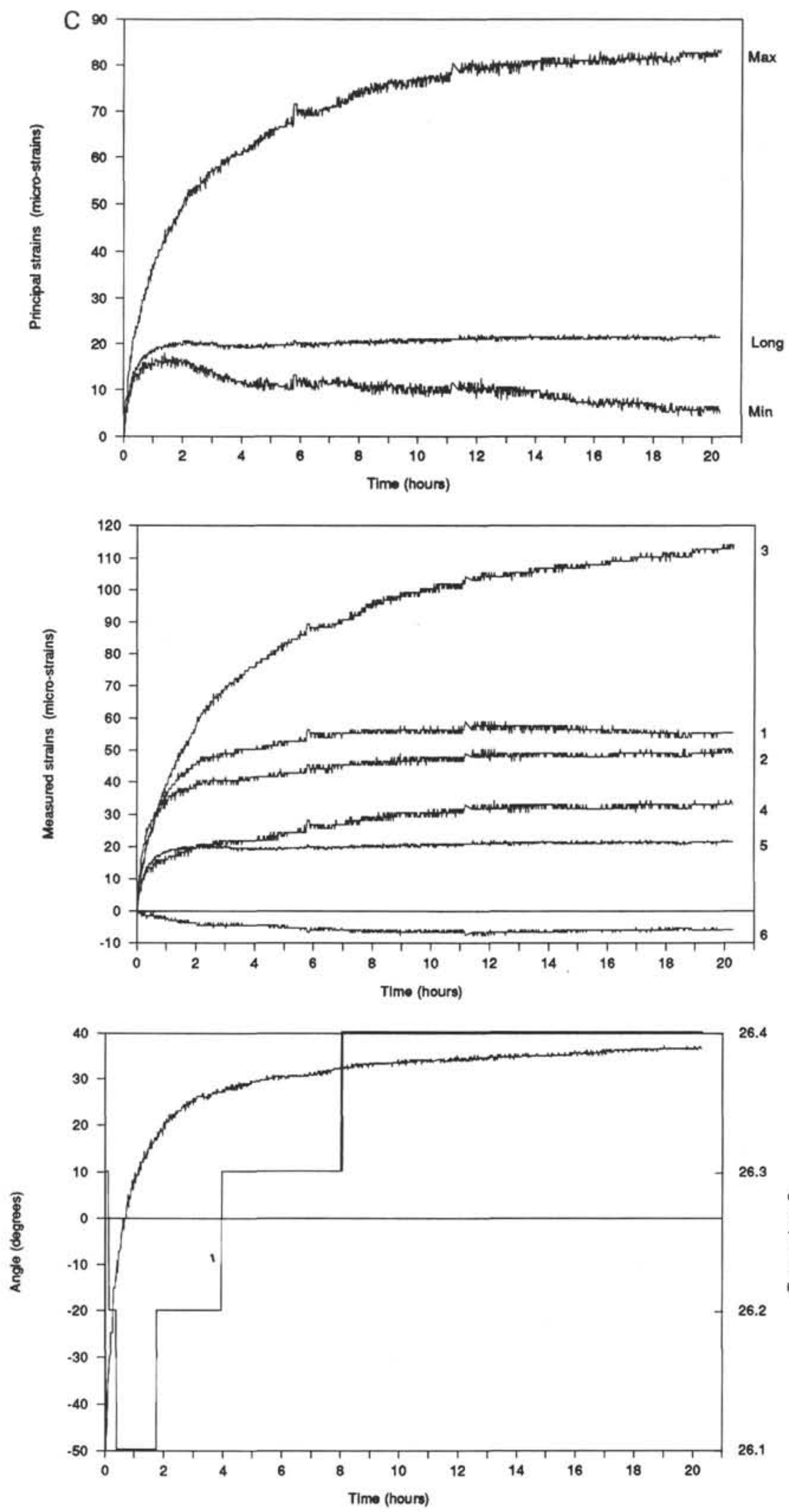

26.4

26.3

Figure 2 (continued). 

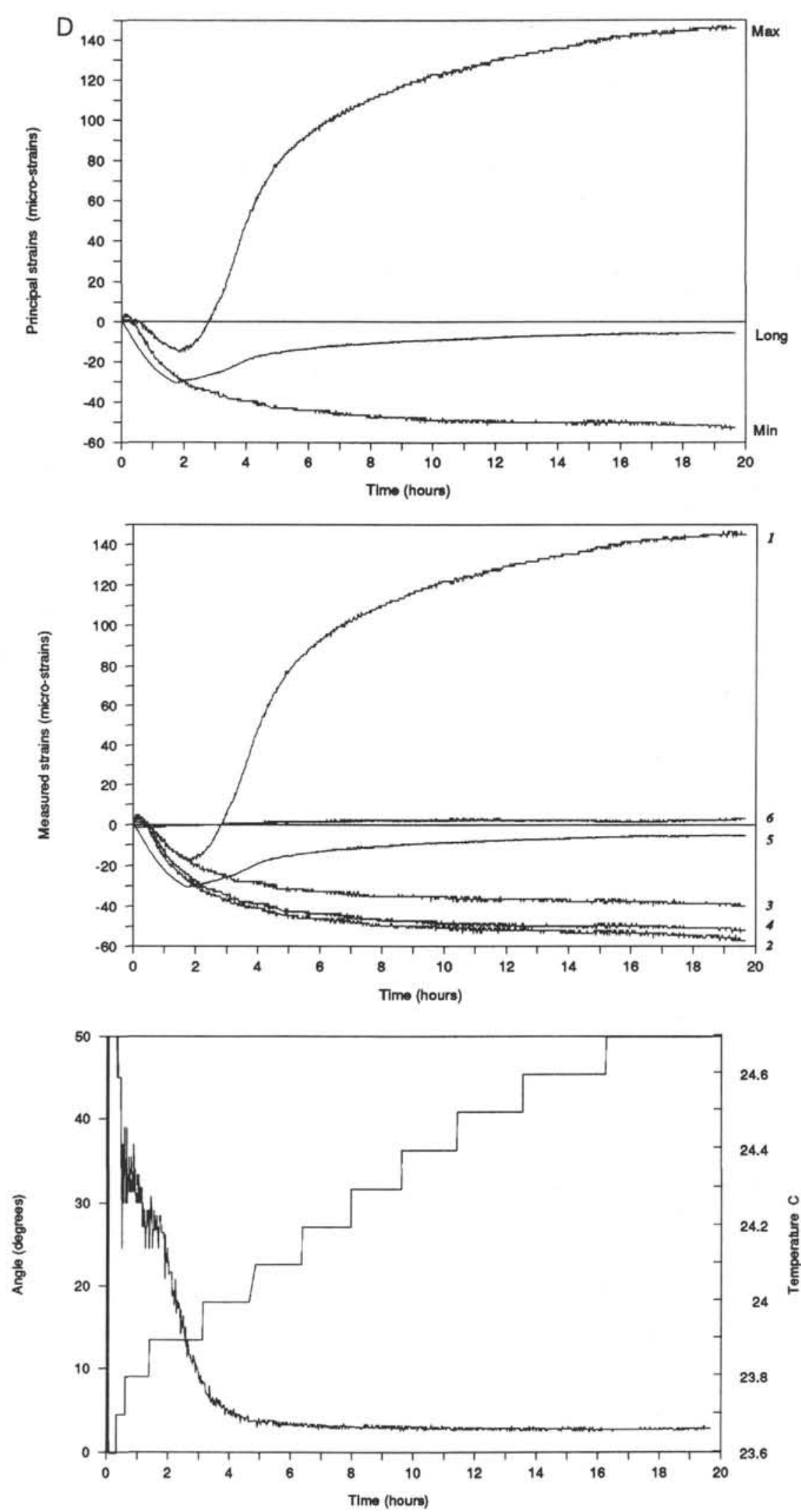

Figure 2 (continued). 
A
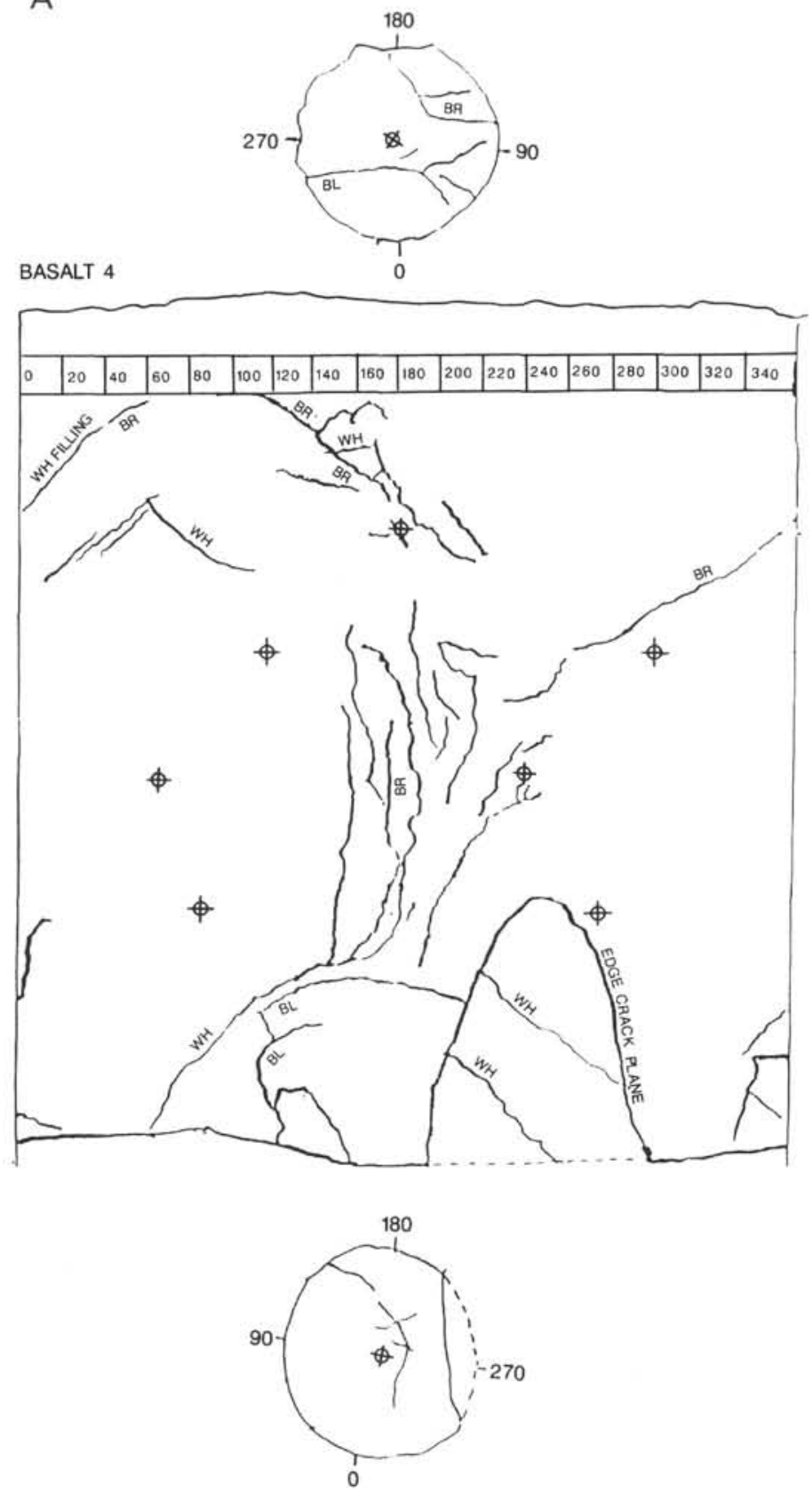
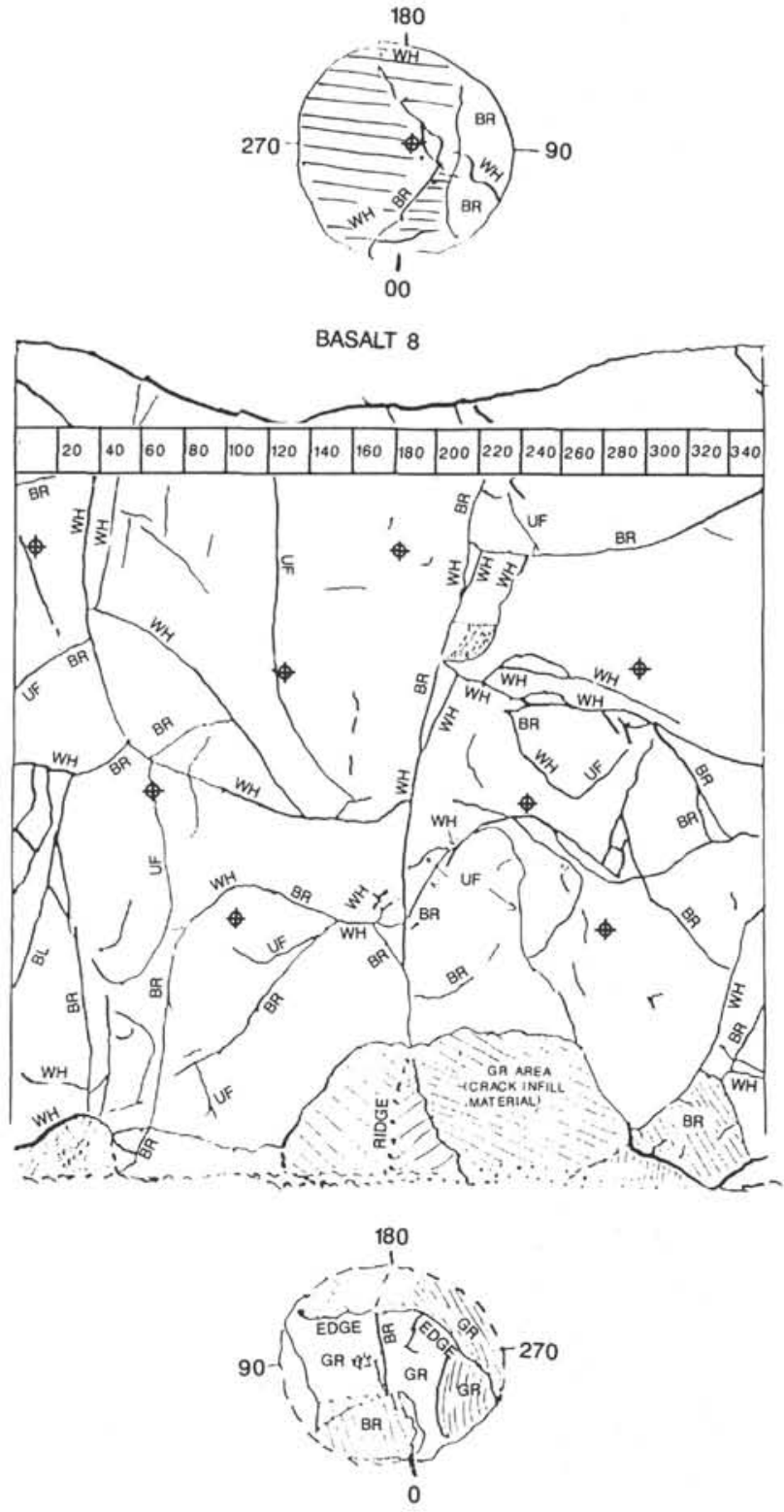

Figure 3. Macro-characterization of the core samples. Tracings for Bas 4 (A), 8 (B), 9 (C), and 12 (D) are shown. In each case, the angular orientation around the core is related to the scribe line.

1. Vesicles: These high-aspect ratio pores are usually filled. Only a few are open, some of which show signs of new crystal growth within. An example of a typical vesicle is shown in Figure $4 \mathrm{~A}$.

2. Larger cracks: Cracks visible in thin section and also observed using the SEM. These include (1) completely sealed cracks filled with calcite, but sometimes with opaques or a green translucent mineral; (2) partly sealed cracks that are now open; (3) open cracks with no evidence of healing (Figs. 4B and 4C). It is possible that the cracks in (2) and (3) may have opened or re-opened as a result of stress release or because of the general stresses of coring. All of the larger cracks traversed the thin section or SEM slice. All have low-aspect ratios, and the open cracks thus will close at low confining pressures.
3. Microcracks: These are observed only with the SEM and are comparable to the basalt crystal sizes or smaller. These include (1) grain boundary cracks, most of which appear to be healed, but some are discontinuous, with evidence of bridging or healing; these can have variable aspect ratios (up to 1.0), but overall represent a minute fraction of the total porosity of the sample (Figs. 4D and 4E); (2) irregular discontinuous fractures that appear to be of "secondary" origin (Fig. 4F); (3) cracks within crystals, which may be associated with crystal structure (Fig. 4G). In this category, the widths of the cracks are typically about $1 \mu \mathrm{m}$, and their contribution to the overall porosity is almost negligible. While some cracks are clearly related to the primary formation of the basalt, others may represent localized stress release, but one cannot say when this occurred. 
C

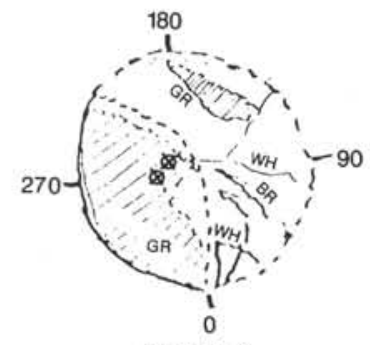

BASALT 9
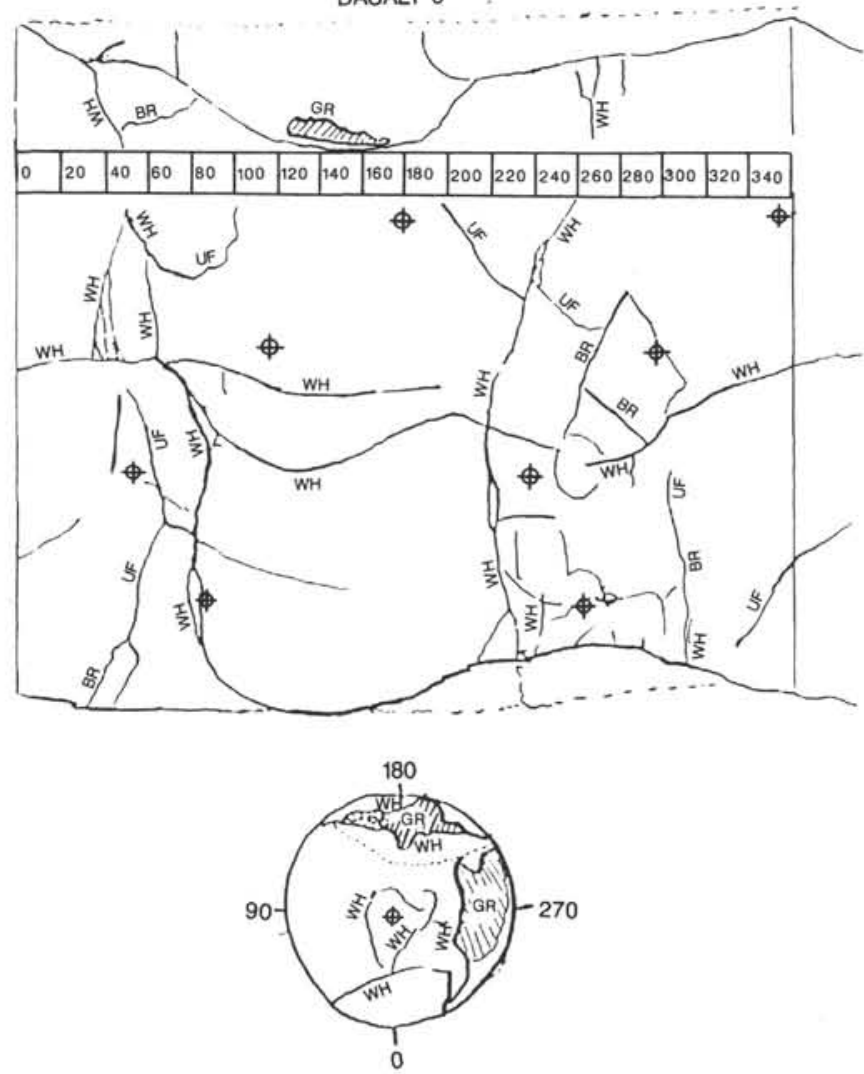

Figure 3 (continued).

The micro-characterization study was not comprehensive, but results indicate that the overall microcrack density and porosity are small. This is in agreement with the findings of Brereton (this volume), where a mean porosity of $3.5 \%$ (ranging from $1.6 \%$ to $8 \%$ ) from 61 determinations was found. Although a range of aspect ratios is evident, it appears that the porosity is contained either within low-aspect ratio cracks (less than 0.05 ) or within cracks having high ratios. The origin of some of the cracks is undoubtedly primary, in that they relate to the formation of the basalt (e.g., vesicles) and to thermal contraction along grain boundaries. Fractures that are filled, or partly so, presumably relate to ocean-floor processes, but the clean cracks or fractures may be related to coring processes, or to strain recovery.
D

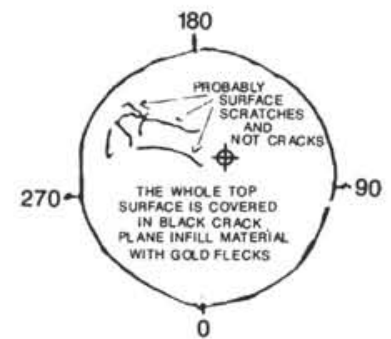

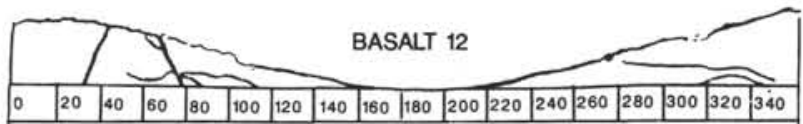
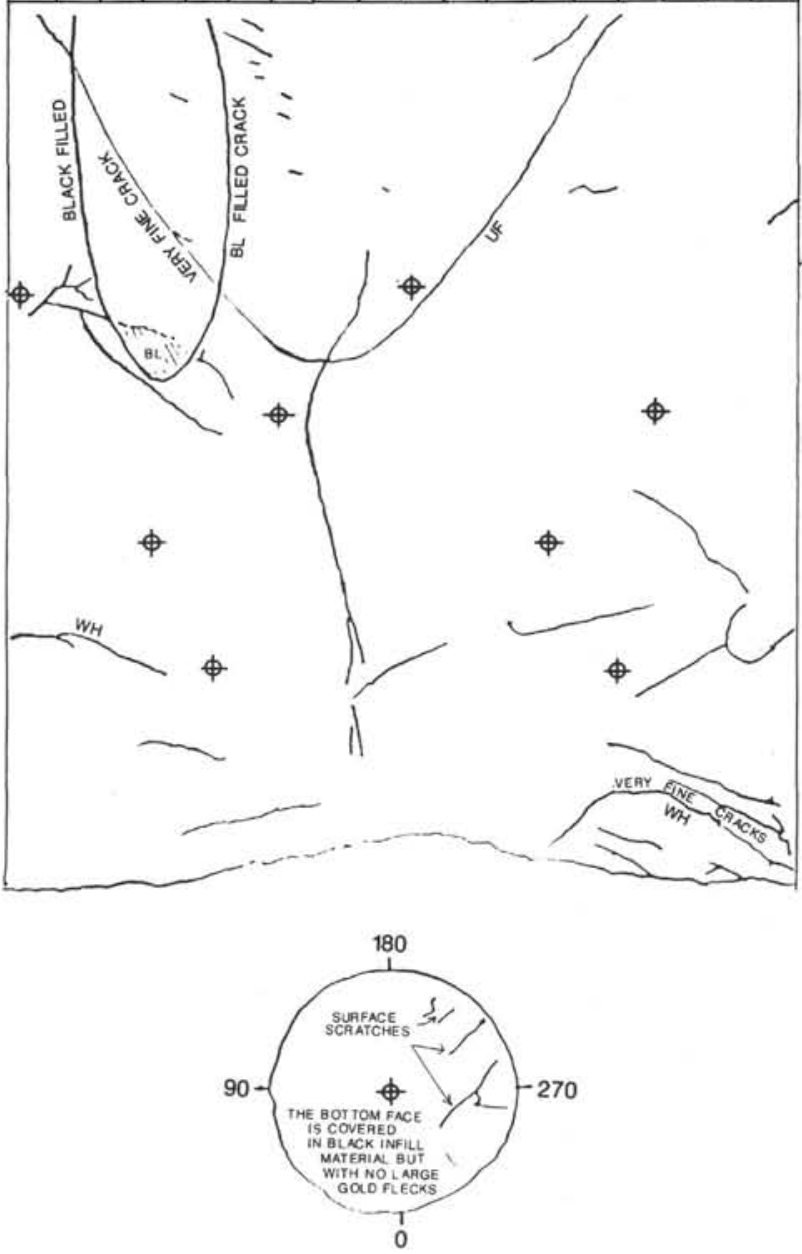

\section{DYNAMIC ELASTIC PROPERTIES}

\section{Subcore Selection and Measurement}

Facilities at the UEA allowed us to measure seismic velocities in rock samples at confining pressures of up to $0.4 \mathrm{GPa}$ with controlled pore pressures. From measurements of density and compressional ( $P$-wave) and shear $(S$-wave) velocities, the elastic properties (bulk modulus, shear modulus, and other parameters) can be determined. The velocities themselves, measured at different orientations, can provide an indication of fracture anisotropy.

Subcores having a diameter of $22 \mathrm{~mm}$ were removed from the core samples Bas $1,4,8,11,12$, and 15 . In almost all cases, five 
A

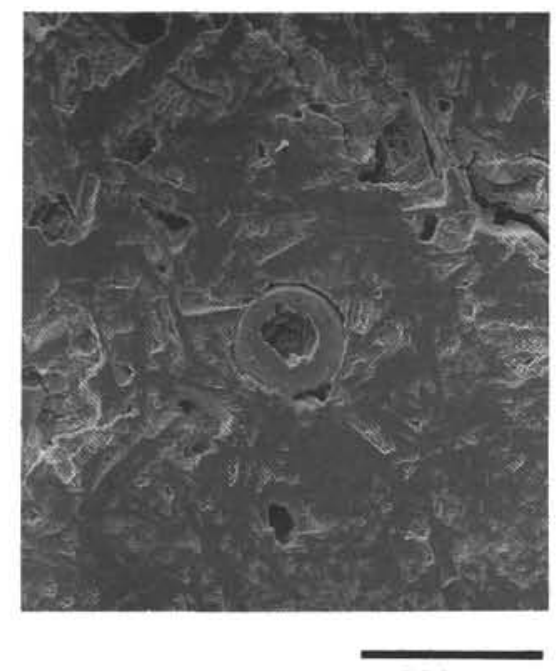

$200 \mu \mathrm{m}$
B

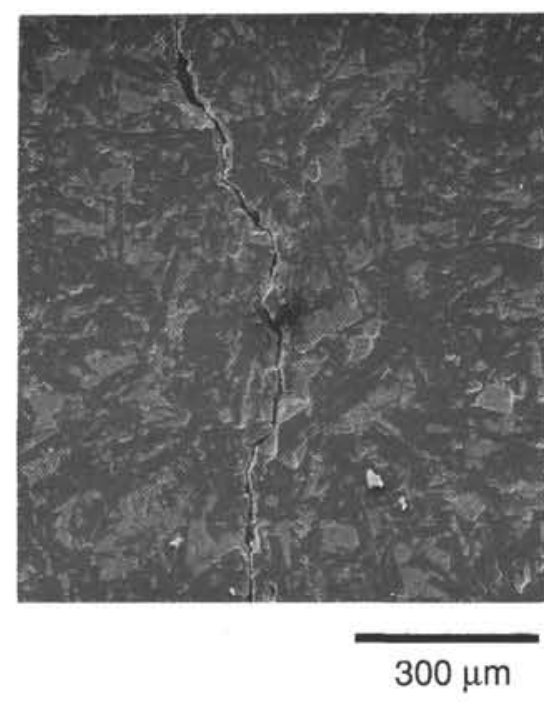

\section{C}

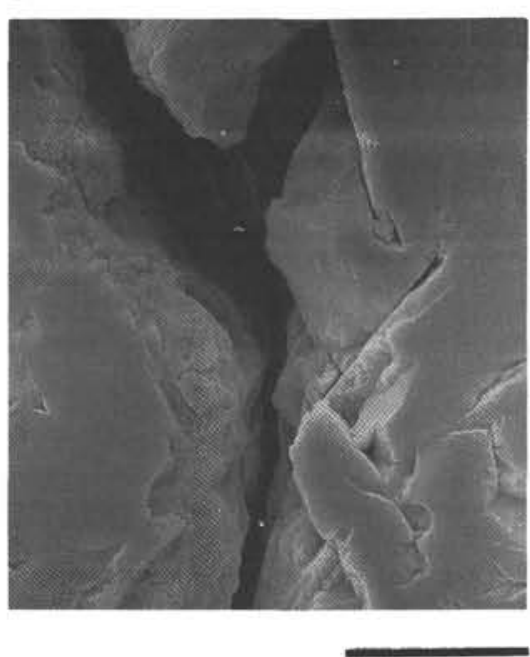

$20 \mu \mathrm{m}$

Figure 4. Electron photomicrographs showing examples of the microcrack features observed. A. Partly filled vesicles with open boundary crack. Other high aspect ratio cracks may result from plucking during sample preparation. B. Typical clean fracture. At this scale, no porosity is visible other than the fracture (and vesicles). C. Detail from B, showing open crack with no evidence of healing. D, E. Grain boundary cracks that are substantially healed, but still show a narrow open crack. F. Localized low-aspect ratio crack. G. Aligned low-aspect ratio cracks associated with crystal structure.

subcores were taken from the same positions where the anelastic strain recoveries were measured, including one from the vertical direction. The ends were trimmed, and all were oriented relative to their position within the core sample. They were vacuum-dried, saturated with seawater, and "dry" and "saturated" densities and apparent porosity were calculated. Thin sections were oriented for each subcore from the trimmed material.

Seismic velocities were measured by a pulse transmission method similar to that of Birch (1960), using lead zirconium titanate transducers having a frequency of $1 \mathrm{MHz}$. The transit time of the pulse across the sample was measured to an accuracy of about $10 \mathrm{~ns}$ for the $P$-wave, resulting in an overall velocity error of about $1 \%$. The $S$-wave velocities (measured separately) were of poorer quality, and some were rejected. Even so, the measurement error is probably about $5 \%$. The vibration direction for the $S$-wave transducer was vertical along the line of the sample, except for the vertical subcore, where it was parallel to the core orientation mark. All measurements were performed on saturated samples, with pore pressure kept at atmospheric pressure.

The in-situ confining pressure on the core materials at Site 765 is about $0.1 \mathrm{GPa}$. Velocities were typically measured at pressures up to a maximum of $0.4 \mathrm{GPa}$, because at these higher pressures most of the microcracks will be closed, which allows one to determine the matrix velocities and elastic properties. At low 
D

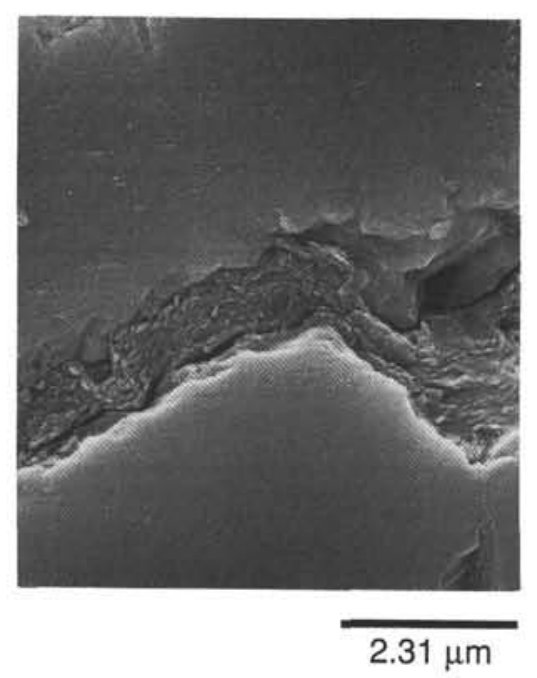

$\mathbf{F}$

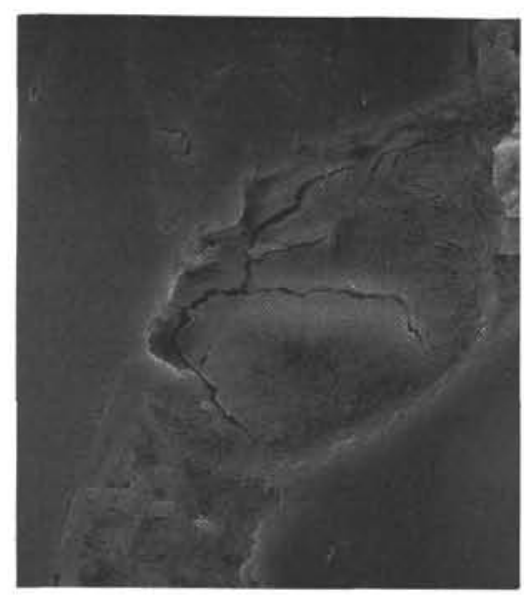

Figure 4 (continued).
$15 \mu \mathrm{m}$
E

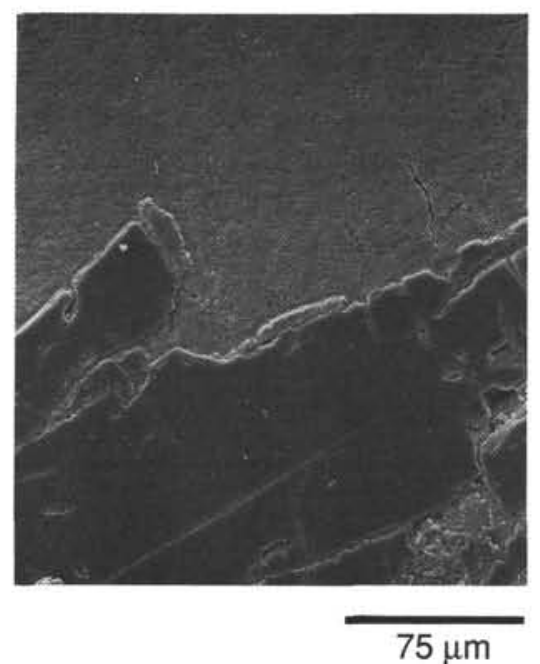

G

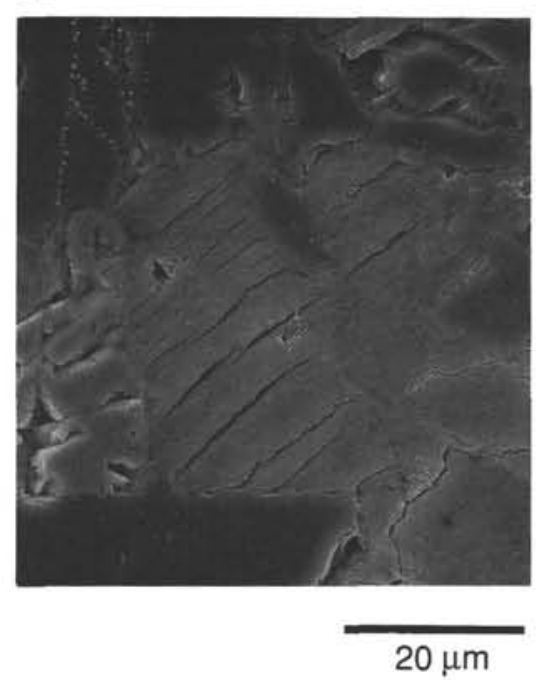

pressures (less than about $0.025 \mathrm{GPa}$ for $P$-waves and $0.05 \mathrm{GPa}$ for $S$-waves) the wave onsets were poor, and thus the velocities were less accurately determined.

\section{Variation of Velocity With Pressure}

Figure 5 depicts the suite of velocity-pressure curves from the core sample Bas 8 . The characteristics of this data set are typical of all of the core samples measured and indicate small increases in velocity with pressure, except for a slightly greater increase at

- the very low end of the pressure range ( 0 to about $0.025 \mathrm{GPa}$ ). The velocity-pressure curves indicate tight rocks, with only low porosities in the form of low-aspect ratio microcracks. Any additional porosity must be in the form of high-aspect ratio pores, which do not close at the pressures applied (Walsh, 1965; Toksoz et al., 1976). Velocities from the reducing part of the pressure cycle were always near those on the increasing part, and the absence of any velocity hysteresis was confirmed by repeated velocity-pressure cycling on some cores. We had intended to examine pore aspect ratio spectra using the inversion method of Cheng and Toksoz (1979), but this would have been of no value given the small velocity variation in these samples. Results from these velocity measurements have been tabulated by Brereton et al. (1990) and are summarized in Table .3.

\section{Velocity Anisotropy}

The velocity differences among the subcores might potentially indicate anisotropy in the large sample, but the results should be regarded with some caution. First, all the anelastic strain recovery measurement points are not on the same plane, but are several centimeters apart along the sample. The macro-scale fractures, often discontinuous, can be distributed unevenly along the core and thus the elastic properties, and hence seismic velocities, of any subcore would be heavily influenced by local irregularities, which may not be a component in an overall simple model of anisotropy. Second, as each subcore is taken from the actual direction of the anelastic strain recovery measurement it should reflect ideally the elastic properties giving rise to the strain recovery curves at that point. However, because the subcores are shorter than the full diameter of the core samples, all components that contributed to the strain recovery curves will not be present. Thus, the macro-characteristics of the cores will be accentuated by the visible fractures, but the dynamic properties will be influenced 

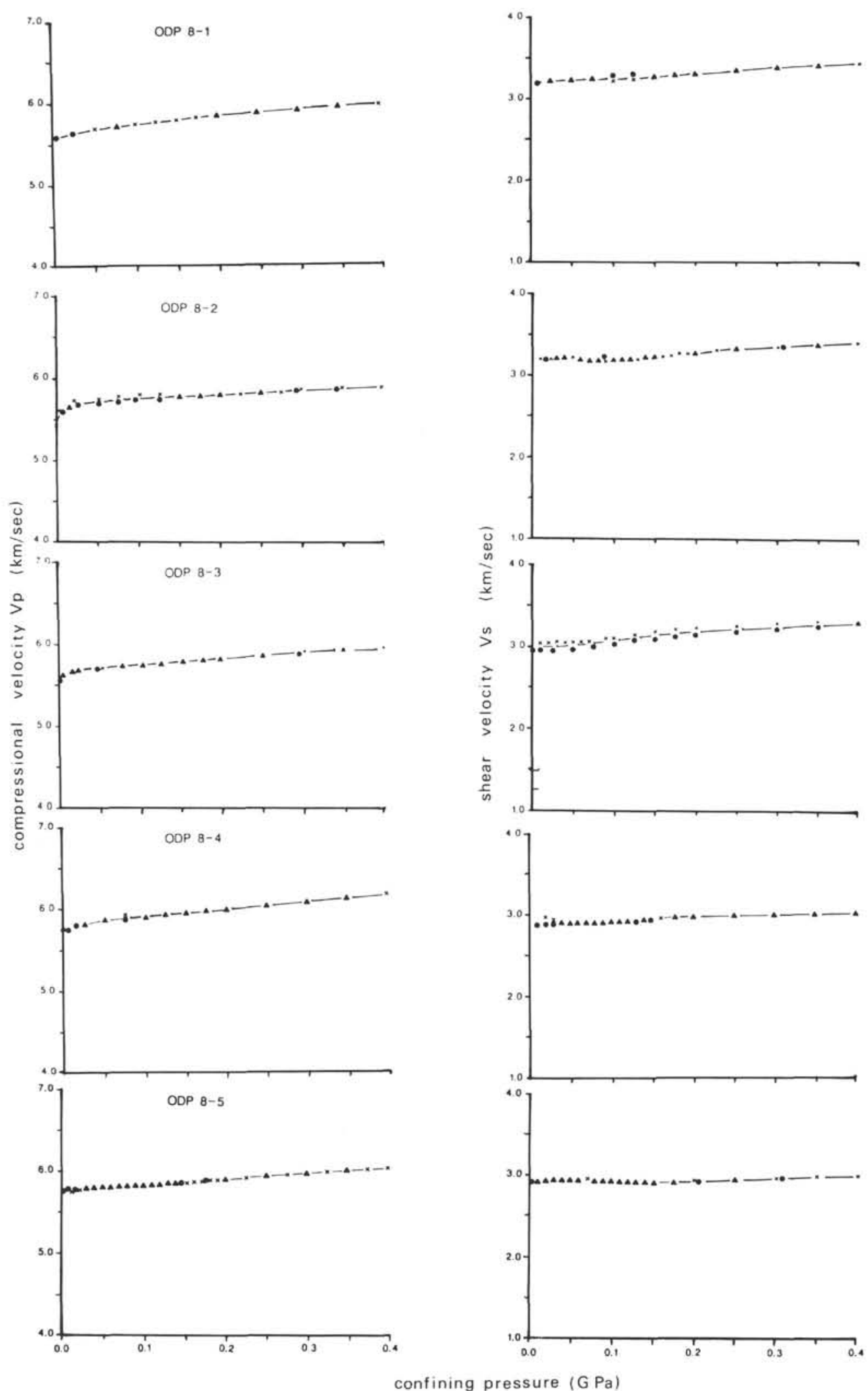

confining pressure $(\mathrm{GPa})$

Figure 5. Velocity-pressure curves for core sample Bas 8 . The symbol $x=a$ measurement at increasing pressure, $\mathrm{o}=$ measurement at decreasing pressure, and $\Delta=$ both measurements having same value. Numbers $8-1,2$, etc., indicate subcores. The curves for this sample are typical and show little velocity variation with pressure. 
Table 3. Variation of $P$ - and $S$-wave seismic velocities with confining pressure for all the subcores measured.

\begin{tabular}{|c|c|c|c|c|c|c|c|c|c|c|c|c|c|c|c|c|}
\hline \multirow[b]{2}{*}{ Sample } & \multirow[b]{2}{*}{ Propagation } & \multirow{2}{*}{$\begin{array}{c}\text { Saturated } \\
\text { density } \\
\left(\mathrm{g} / \mathrm{m}^{3}\right)\end{array}$} & \multicolumn{14}{|c|}{ Pressure (GPa) } \\
\hline & & & 0.0 & 0.01 & 0.025 & 0.05 & 0.075 & 0.10 & 0.125 & 0.15 & 0.175 & 0.20 & 0.25 & 0.30 & 0.35 & 0.40 \\
\hline BAS01-1 & P & 2.835 & 5.60 & 5.72 & 5.72 & 5.77 & 5.80 & 5.83 & 5.87 & 5.88 & 5.91 & 5.93 & 5.96 & 5.97 & 5.98 & 6.01 \\
\hline BAS01-1 & $\mathrm{S}$ & 2.835 & 3.13 & 3.14 & 3.16 & 3.18 & 3.19 & 3.20 & 3.22 & 3.23 & 3.24 & 3.26 & 3.27 & 3.28 & 3.30 & 3.30 \\
\hline BAS01-2 & $\mathrm{P}$ & 2.857 & 5.54 & 5.56 & 5.70 & 5.71 & 5.72 & 5.72 & 5.73 & 5.74 & 5.75 & 5.76 & 5.79 & 5.80 & 5.80 & 5.82 \\
\hline BAS01-3 & $\mathbf{P}$ & 2.866 & 5.75 & 5.86 & 5.89 & 5.93 & 5.93 & 5.96 & 5.97 & 5.97 & 5.98 & 5.99 & 5.98 & 5.98 & 5.98 & 6.00 \\
\hline BAS01-3 & $\mathrm{S}$ & 2.866 & 3.14 & 3.22 & 3.25 & 3.25 & 3.25 & 3.27 & 3.29 & 3.30 & 3.31 & 3.32 & 3.31 & 3.31 & 3.30 & 3.30 \\
\hline BAS01-4 & $\mathbf{P}$ & 2.789 & 5.40 & 5.50 & 5.55 & 5.58 & 5.59 & 5.60 & 5.62 & 5.62 & 5.63 & 5.64 & 5.68 & 5.70 & 5.73 & 5.74 \\
\hline BAS01-4 & $\mathrm{S}$ & 2.789 & 2.99 & 3.00 & 3.02 & 3.05 & 3.06 & 3.08 & 3.10 & 3.12 & 3.13 & 3.15 & 3.17 & 3.20 & 3.22 & 3.22 \\
\hline BAS01-5 & $\mathrm{P}$ & 2.841 & 5.52 & 5.57 & 5.60 & 5.63 & 5.63 & 5.64 & 5.67 & 5.67 & 5.67 & 5.68 & 5.69 & 5.70 & 5.74 & 5.75 \\
\hline BAS01-5 & $\mathrm{S}$ & 2.841 & 2.83 & 2.85 & 2.86 & 2.86 & 2.86 & 2.87 & 2.90 & 2.92 & 2.94 & 2.95 & 3.00 & 3.02 & 3.03 & 3.05 \\
\hline BAS04-1 & $\mathrm{P}$ & 2.869 & 5.90 & 5.94 & 5.95 & 5.97 & 5.99 & 6.00 & 6.00 & 6.02 & 6.07 & 6.05 & 6.08 & 6.11 & 6.15 & 6.18 \\
\hline BAS04-1 & $\mathrm{S}$ & 2.869 & 2.98 & 3.00 & 3.02 & 3.03 & 3.04 & 3.05 & 3.06 & 3.08 & 3.12 & 3.15 & 3.17 & 3.20 & 3.24 & 3.28 \\
\hline BAS04-2 & $\mathrm{P}$ & 2.865 & 5.73 & 5.75 & 5.78 & 5.80 & 5.83 & 5.87 & 5.89 & 5.90 & 5.90 & 5.92 & 5.96 & 6.00 & 6.03 & 6.05 \\
\hline BAS04-3 & $\mathrm{P}$ & 2.816 & 5.35 & 5.44 & 5.55 & 5.60 & 5.60 & 5.65 & 5.69 & 5.70 & 5.72 & 5.75 & 5.78 & 5.80 & 5.83 & 5.87 \\
\hline BAS04-3 & $\mathrm{S}$ & 2.816 & 2.80 & 2.80 & 2.80 & 2.80 & 2.81 & 2.83 & 2.86 & 2.87 & 2.88 & 2.91 & 2.93 & 2.95 & 2.97 & 2.98 \\
\hline BAS04-4 & $\mathbf{P}$ & 2.860 & 5.35 & 5.68 & 5.73 & 5.78 & 5.80 & 5.83 & 5.90 & 5.92 & 5.94 & 5.95 & 6.00 & 6.02 & 6.15 & 6.08 \\
\hline BAS04-5 & $\mathrm{P}$ & 2.970 & 5.90 & 6.11 & 6.15 & 6.18 & 6.20 & 6.23 & 6.25 & 6.28 & 6.29 & 6.30 & 6.30 & 6.30 & 6.32 & 6.33 \\
\hline BAS04-5 & $S$ & 2.970 & - & - & - & - & 3.10 & 3.12 & 3.18 & 3.22 & 3.24 & 3.25 & 3.28 & 3.33 & 3.36 & 3.38 \\
\hline BAS08-1 & $\mathrm{P}$ & 2.878 & 5.60 & 5.61 & 5.63 & 5.70 & 5.72 & 5.78 & 5.80 & 5.82 & 5.85 & 5.85 & 5.89 & 5.92 & 5.95 & 5.95 \\
\hline BAS08-1 & $\mathrm{S}$ & 2.878 & 3.15 & 3.18 & 3.20 & 3.24 & 3.25 & 3.25 & 3.27 & 3.28 & 3.29 & 3.32 & 3.35 & 3.38 & 3.40 & 3.43 \\
\hline BAS $08-2$ & $\mathrm{P}$ & 2.882 & 5.43 & 5.65 & 5.70 & 5.73 & 5.78 & 5.81 & 5.81 & 5.82 & 5.83 & 5.83 & 5.85 & 5.89 & 5.90 & 5.90 \\
\hline BAS $08-2$ & $\mathrm{~S}$ & 2.882 & 3.18 & 3.20 & 3.20 & 3.20 & 3.19 & 3.22 & 3.23 & 3.24 & 3.27 & 3.30 & 3.35 & 3.38 & 3.40 & 3.43 \\
\hline BAS08-3 & $\mathrm{P}$ & 2.878 & 5.55 & 5.64 & 5.68 & 5.72 & 5.75 & 5.76 & 5.78 & 5.80 & 5.82 & 5.83 & 5.88 & 5.90 & 5.92 & 5.96 \\
\hline BAS08-3 & $\mathrm{S}$ & 2.878 & 2.98 & 2.98 & 2.99 & 3.00 & 3.03 & 3.05 & 3.10 & 3.15 & 3.17 & 3.18 & 3.21 & 3.25 & 3.27 & 3.28 \\
\hline BAS08-4 & $\mathrm{P}$ & 2.930 & 5.75 & 5.78 & 5.82 & 5.87 & 5.90 & 5.91 & 5.93 & 5.95 & 5.98 & 6.00 & 6.02 & 6.07 & 6.10 & 6.15 \\
\hline BAS08-4 & $\mathrm{S}$ & 2.930 & 2.85 & 2.87 & 2.88 & 2.89 & 2.89 & 2.90 & 2.93 & 2.95 & 2.96 & 2.97 & 2.98 & 3.00 & 3.00 & 3.00 \\
\hline BAS08-5 & $\mathrm{P}$ & 2.909 & 5.75 & 5.75 & 5.79 & 5.80 & 5.82 & 5.83 & 5.85 & 5.85 & 5.89 & 5.91 & 5.95 & 5.98 & 6.02 & 6.05 \\
\hline BAS08-5 & $\mathrm{S}$ & 2.909 & 2.90 & 2.91 & 2.92 & 2.95 & 2.93 & 2.93 & 2.93 & 2.92 & 2.92 & 2.94 & 2.95 & 2.96 & 2.97 & 2.98 \\
\hline BAS11-1 & $\mathrm{P}$ & 2.813 & 4.98 & 5.15 & 5.23 & 5.29 & 5.32 & 5.35 & 5.36 & 5.38 & 5.39 & 5.40 & 5.42 & 5.45 & 5.46 & 5.50 \\
\hline BAS11-1 & $\mathrm{S}$ & 2.813 & 2.80 & 2.82 & 2.82 & 2.85 & 2.87 & 2.90 & 2.93 & 2.93 & 2.96 & 2.97 & 2.99 & 3.00 & 3.00 & 3.00 \\
\hline BAS11-2 & $\mathbf{P}$ & 2.712 & 5.02 & 5.07 & 5.15 & 5.21 & 5.26 & 5.28 & 5.30 & 5.32 & 5.35 & 5.37 & 5.42 & 5.48 & 5.54 & 5.57 \\
\hline BAS11-2 & $\mathrm{S}$ & 2.712 & 2.55 & 2.72 & 2.73 & 2.75 & 2.76 & 2.77 & 2.78 & 2.79 & 2.80 & 2.80 & 2.82 & 2.84 & 2.85 & 2.87 \\
\hline BAS11-3 & $\mathrm{P}$ & 2.832 & 5.28 & 5.45 & 5.53 & 5.58 & 5.60 & 5.62 & 5.64 & 5.65 & 5.68 & 5.70 & 5.72 & 5.77 & 5.86 & 5.83 \\
\hline BAS11-3 & $\mathrm{S}$ & 2.832 & 3.03 & 3.03 & 3.05 & 3.05 & 3.03 & 3.03 & 3.04 & 3.04 & 3.04 & 3.05 & 3.03 & 3.01 & 3.01 & 3.05 \\
\hline BAS11-4 & $\mathrm{P}$ & 2.791 & 5.35 & 5.39 & 5.42 & 5.45 & 5.48 & 5.50 & 5.52 & 5.54 & 5.55 & 5.58 & 5.62 & 5.65 & 5.70 & 5.73 \\
\hline BAS11-4 & S & 2.791 & 2.72 & 2.76 & 2.82 & 2.86 & 2.88 & 2.88 & 2.89 & 2.90 & 2.93 & 2.96 & 2.99 & 3.00 & 3.00 & 3.00 \\
\hline BAS11-5 & $\mathbf{P}$ & 2.830 & 5.57 & 5.60 & 5.62 & 5.65 & 5.67 & 5.68 & 5.70 & 5.70 & 5.72 & 5.74 & 5.78 & 5.80 & 5.84 & 5.87 \\
\hline BAS11-5 & S & 2.830 & 2.91 & 2.91 & 2.90 & 2.93 & 2.94 & 2.95 & 2.96 & 2.97 & 3.00 & 3.00 & 3.03 & 3.03 & 3.03 & 3.03 \\
\hline BAS $12-1$ & $\mathrm{P}$ & 2.819 & 5.35 & 5.53 & 5.65 & 5.72 & 5.74 & 5.75 & 5.78 & 5.80 & 5.80 & 5.82 & 5.87 & 5.89 & 5.90 & 5.92 \\
\hline BAS12-1 & $\mathrm{S}$ & 2.819 & - & - & - & - & - & - & - & - & 2.85 & 2.93 & 2.98 & 3.01 & 3.04 & 3.05 \\
\hline BAS12-2 & $\mathrm{P}$ & 2.837 & 5.15 & 5.39 & 5.45 & 5.50 & 5.52 & 5.55 & 5.59 & 5.60 & 5.62 & 5.62 & 5.68 & 5.70 & 5.72 & 5.73 \\
\hline BAS $12-2$ & $S$ & 2.837 & - & 2.95 & 2.96 & 2.97 & 2.98 & 3.00 & 3.02 & 3.05 & 3.07 & 3.10 & 3.15 & 3.20 & 3.22 & 3.25 \\
\hline BAS12-3 & $\mathrm{P}$ & 2.847 & 4.95 & 5.15 & 5.25 & 5.30 & 5.36 & 5.38 & 5.42 & 5.45 & 5.47 & 5.50 & 5.58 & 5.65 & 5.72 & 5.80 \\
\hline BAS12-3 & $\mathrm{S}$ & 2.847 & - & 2.50 & 3.03 & 3.05 & 3.06 & 3.07 & 3.07 & 3.09 & 3.11 & 3.13 & 3.15 & 3.20 & 3.25 & 3.28 \\
\hline BAS12-4 & $\mathrm{P}$ & 2.850 & 5.35 & 5.58 & 5.63 & 5.68 & 5.70 & 5.72 & 5.72 & 5.73 & 5.74 & 5.75 & 5.79 & 5.82 & 5.86 & 5.88 \\
\hline BAS12-4 & $\mathrm{S}$ & 2.850 & 2.98 & 3.02 & 3.03 & 3.04 & 3.05 & 3.06 & 3.07 & 3.07 & 3.07 & 3.08 & 3.10 & 3.12 & 3.14 & 3.15 \\
\hline BAS12-5 & $\mathbf{P}$ & 2.840 & 5.25 & 5.52 & 5.58 & 5.63 & 5.65 & 5.66 & 5.69 & 5.70 & 5.72 & 5.73 & 5.76 & 5.78 & 5.82 & 5.85 \\
\hline BAS12-5 & S & 2.840 & 2.95 & 2.93 & 2.93 & 2.93 & 2.92 & 2.92 & 2.94 & 2.97 & 3.00 & 3.02 & 3.05 & 3.08 & 3.12 & 3.10 \\
\hline BAS15-1 & P & 2.928 & 5.77 & 5.98 & 6.07 & 6.12 & 6.13 & 6.14 & 6.15 & 6.17 & 6.18 & 6.20 & 6.20 & 6.23 & 6.25 & 6.25 \\
\hline BAS15-1 & $\mathrm{S}$ & 2.928 & 3.40 & 3.42 & 3.43 & 3.45 & 3.49 & 3.51 & 3.52 & 3.55 & 3.55 & 3.57 & 3.55 & 3.60 & 3.64 & 3.67 \\
\hline BAS $15-2$ & $\mathrm{P}$ & 2.933 & 6.00 & 6.02 & 6.05 & 6.10 & 6.12 & 6.14 & 6.16 & 6.18 & 6.20 & 6.22 & 6.26 & 6.30 & 6.33 & 6.35 \\
\hline BAS $15-2$ & $S$ & 2.933 & 3.40 & 3.40 & 3.42 & 3.45 & 3.49 & 3.51 & 3.52 & 3.54 & 3.55 & 3.57 & 3.59 & 3.60 & 3.64 & 3.66 \\
\hline BAS $15-3$ & $\mathrm{P}$ & 2.918 & 5.98 & 6.00 & 6.03 & 6.06 & 6.10 & 6.13 & 6.15 & 6.16 & 6.18 & 6.19 & 6.22 & 6.25 & 6.28 & 6.30 \\
\hline BAS $15-3$ & $\mathrm{~S}$ & 2.918 & 3.35 & 3.32 & 3.30 & 3.28 & 3.30 & 3.33 & 3.36 & 3.38 & 3.40 & 3.40 & 3.42 & 3.45 & 3.48 & 3.50 \\
\hline BAS $15-4$ & $\mathrm{P}$ & 2.922 & 5.99 & 6.00 & 6.04 & 6.06 & 6.08 & 6.10 & 6.13 & 6.14 & 6.15 & 6.17 & 6.20 & 6.24 & 6.27 & 6.30 \\
\hline BAS $15-5$ & $\mathrm{P}$ & 2.929 & 5.75 & 6.00 & 6.03 & 6.06 & 6.08 & 6.10 & 6.14 & 6.16 & 6.18 & 6.19 & 6.23 & 6.28 & 6.30 & 6.35 \\
\hline BAS15-5 & $\mathrm{S}$ & 2.929 & - & 3.00 & 3.15 & 3.17 & 3.20 & 3.22 & 3.25 & 3.28 & 3.30 & 3.32 & 3.35 & 3.35 & 3.37 & 3.38 \\
\hline
\end{tabular}

heavily by the matrix properties and any larger fractures that cut the subcore. This is a scale effect that has been introduced among the core samples and the subcores.

A summary of the $P$ and $S$-wave velocities $\left(V_{p}\right.$ and $\left.V_{s}\right)$ with respect to their orientation is shown in Figure 6. For the cores Bas 1,4 , and 11 , the $P$-wave velocity differences among the subcores is greater than the likely error, and the velocity distribution suggests that these differences can be substantially explained by a simple velocity ellipse. Bas 8 shows velocity variation, but within the possible error, and for Bas 15 , the velocity differences are not significant. Bas 12 subcores show variations that are slightly greater than the errors, but the four directions (perpendicular to the axis of the core) show alternating high and low values. Such a pattern of anisotropy may be explained by intersecting fracture planes, whereas the simple "anisotropy" shown by the cores Bas 1,4 , and 11 may reflect one dominant fracture orientation parallel to the high-velocity direction (for example, see Crampin et al., 1980).

Such dominant fracture orientations were not seen on these cores, and the velocity measurements suggest only some dependence on the macro-crack characteristics. However, a comparison of these velocity anisotropy results with the anelastic strain recovery results does provide some evidence to support the view that values of $V_{\mathrm{p}}$ should be least in the direction of maximum strain recovery and greatest in the direction of minimum strain recovery. This is entirely true for sample Bas 8 , while for samples Bas 1 and 
P-WAVE

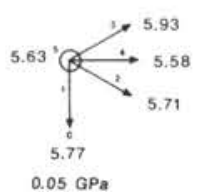

S-WAVE

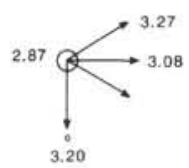

ODP CORE 4

P-WAVE

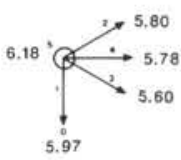

$0.05 \mathrm{GPa}$

S-WAVE
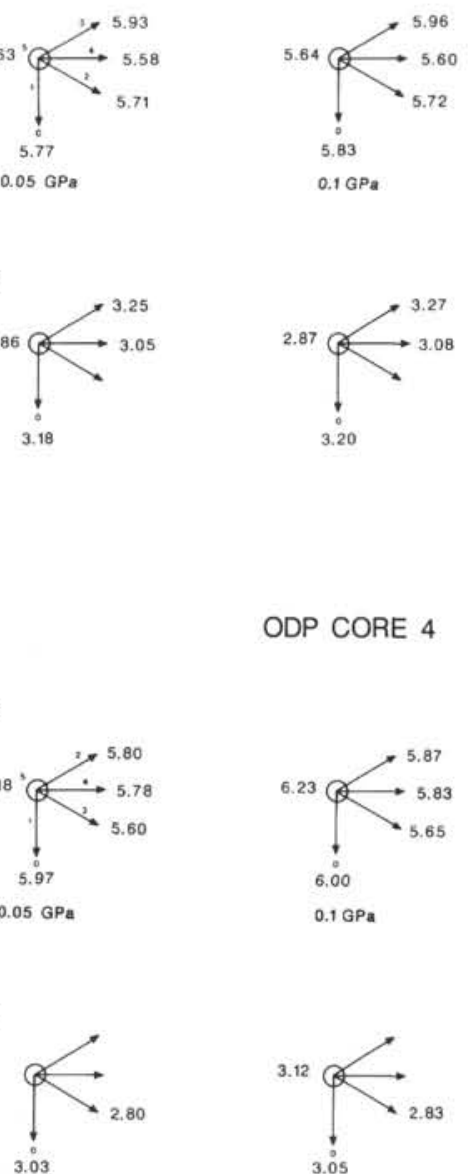

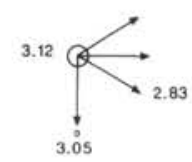

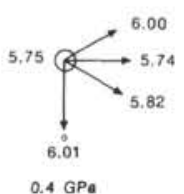

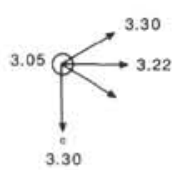

S-WAVE
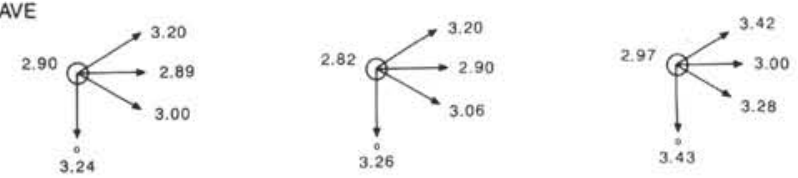

ODP CORE 11

P-WAVE

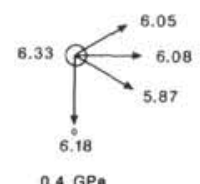

$0.1 \mathrm{GPa}$

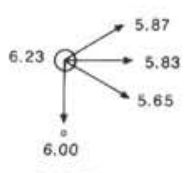

$0.4 \mathrm{GPa}$

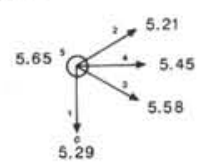

$0.05 \mathrm{GPa}$

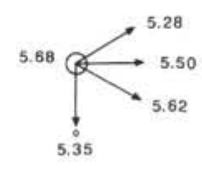

$0.1 \mathrm{GPa}$

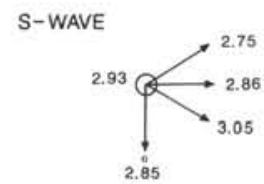

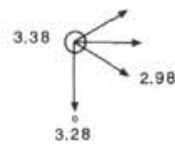

P-WAVE
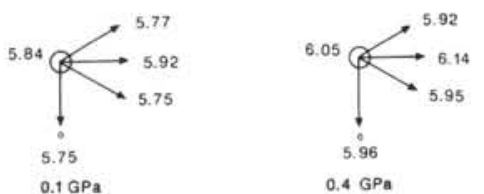

$0.4 \mathrm{GPa}$

Figure 6. Measured $P$ - and $S$-wave velocities at $0.05,0.1$, and $0.4 \mathrm{GPa}$ pressures, plotted according to subcore orientations. The symbol o on the 0.05 $\mathrm{GPa}$ plot $=$ direction of scribe line, and other symbols refer to subcore numbers. Unreliable $S$-wave velocities have not been included.

Bas 4 , the minimum values of $V_{p}$ correspond to the LVDT positions that recorded the maximum strain recovery. The opposite is the case for Bas 12 , but this sample produced anomalous strain recovery results that may be attributed to the prominent sine wave fracture noted during macro-characterization. Results from Bas 11 and 15 were less conclusive.

Complete core shear-wave velocity anisotropy measurements were performed on samples Bas 13 and 14 at Imperial College. The results for Bas 14 were inconclusive, but those for Bas 13 showed a clear correlation between the orientation of minimum $V \mathrm{~s}$ and the orientation of maximum strain recovery.

\section{Elastic Moduli}

For each subcore, the apparent elastic moduli (and other parameters) can be calculated from the respective $P$ and $S$-wave velocities and densities. The moduli are not necessarily true values because only simple equations were used that assume isotropic elastic behavior. The determined velocities and derived parameters for each subcore at varying pressures have been tabulated by Brereton et al. (1990) and are summarized in Table 4 for $0.1-\mathrm{GPa}$ confining pressure.

\section{DISCUSSION AND CONCLUSIONS}

Three sets of experiments were conducted on the basalt samples collected during Leg 123: anelastic strain recovery monitor- ing, dynamic elastic property measurements, and thermal azimuthal anisotropy observations. In addition, a range of other tests and observations was recorded to characterize each sample. One feature common to the experimental results and observations is that no apparently consistent orientation trend occurs either among the different measurements from each core sample or among the same sets of measurements for the various core samples. However, some evidence of correspondence between velocity anisotropy and anelastic strain recovery exists, but this is not consistent for all the core samples investigated.

The thermal azimuthal anisotropy observations, although showing no conclusive correlations with the other results, were of significant interest in that they clearly exhibited anisotropic behavior. The apparent reproducibility of this behavior may point toward the possibility that rocks retain a "memory" of their stress history, which might be exploited to derive stress orientations from archived core.

Thin sections do not provide any evidence of crack orientation, other than that seen by eye, but electron microscopy analysis indicates (1) partly sealed cracks that have become open, (2) open cracks with no sign of healing, and (3) irregular discontinuous microcracks, some of which may represent localized stress release. Such a mechanism of stress release should accord with the acoustic emission events observed by Wolter and Berckhemer (1989). In contrast, the rock matrix appears to be isotropic, with 


\section{ODP CORE 12}

P-WAVE

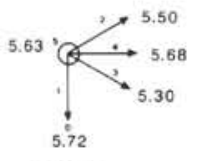

$0.1 \mathrm{GPa}$

S- WAVE

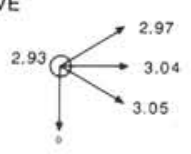

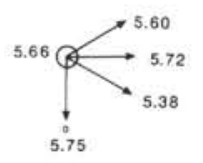

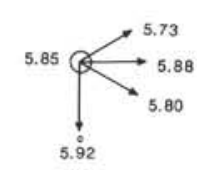

$0.4 \mathrm{GPa}$

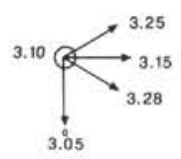

ODP CORE 15

P-WAVE

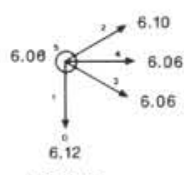

$0.05 \mathrm{GPa}$

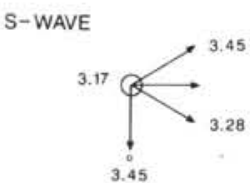

Figure 6 (continued).

no evidence of crystal alignment. Even though the microcracks exhibit a range of aspect ratios, the observed porosity is generally low. Very low- (less than 0.01 ) or high- (vesicles) aspect ratios dominate. Velocity variations with pressure confirmed that the basalts are "tight," while $P$-wave velocities indicate significant anisotropy.

The strain recovery measuring equipment developed for this study proved to be most effective and behaved without fault. We were able to measure strains to within about 1.5 microstrains over long periods and to reduce to a minimum the effects of temperature variation on both the equipment and the core samples. We have demonstrated that the effects of thermal stability within the basalt cores are generally small relative to the magnitudes of the total strains recorded and also that these effects can ostensibly be ignored after about the first hour of measurement. Therefore, systematic equipment errors and core-sample thermal stabilization effects can be discounted as explanations for the anomalous behavior of some of these basalt cores.

Anelastic strain recovery is a relatively new technique. When experimental results were first reported, much of the work was being done using hydrocarbon reservoir rocks, and close agreement with other stress-measurement methods generally was found. Most of the early data presentations tended to follow the somewhat "classical" power law strain recovery curves whereby core samples expanded asymptotically with time. These and the more recent studies seem to indicate that when the method is applied to relatively straightforward, isotropic sediments, the results can be regarded as yielding reliable and reproducible measures of stress magnitude and orientation.

Because the method has been applied to an increasingly wide range of rock types, the literature has begun to include examples of rocks that contract with time. Explanations for this "nonclassical" behavior have been difficult to verify, but strong circumstantial evidence exists to suggest that core-sample contractions result from the slow diffusion of pore fluids from a preexisting microcrack structure, permitting the rock to deflate at a greater rate than the expansion caused by anelastic strain recovery. Scientists had generally assumed that drilling takes place under near-balanced conditions, such that pore fluid pressures remain at equilibrium with drilling fluid pressures and that the permeability of the core material is sufficiently high to allow for maintaining this equilibrium during core recovery. This will not be so if a low core material permeability prevents these differential pressures from maintaining equilibrium during and subsequent to core retrieval. Therefore, for low-permeability materials, such as siltstones, mudstones and basalts, it is possible that the two processes of anelastic strain recovery and pore pressure recovery will compete with one another. The characteristics of the resulting strain recovery curve will depend upon the magnitudes of the rock stresses, the permeability, and the pore pressure.

One of the basic assumptions of anelastic strain recovery is that the rock is rheologically isotropic; that is, it exhibits the same time-dependent behavior in all directions. It is evident that these basalt cores have been intersected by an abundance of fractures, some of which pass right through the samples, but many have been intercepted or terminate within the rock matrix. The behavior of these core samples thus will be influenced, not only by the properties of the rock matrix between the fractures, but also by how these macro- and micro-scale fractures mutually interact.

The behavior of three core samples is worthy of note:

1. Bas 1: It is possible that the negative responses of all the gauges may be related to one subvertical and impersistent set of fractures that terminate within the rock matrix, located at about $180^{\circ}$ from the scribe line.

2. Bas 12: The atypical responses of the first horizontal and vertical gauges, which initially contract but then expand, may be attributed to the fact that only they are set across a prominent sinusoidal fracture intersected by a subvertical fracture.

3. Bas 15: Although the macro-characterization of this core described little sign of fracturing, the response curve of the vertical gauge showed persistent contraction.

Although correlations between the strain recovery curve responses and the more complex fracture characteristics are difficult, a general observation may be that an anomalous response can be associated with a measurement across, or close to, a fracture. Yasunaga (1989) discussed the possibility that shear displacement along an impersistent fracture may result in apparent contractions and apparent expansions for different sets of gauges, depending upon the locations of the gauges relative to the fracture plane.

The theoretical models reported in the literature were not applied to the Leg 123 strain recovery results at this stage for two reasons: (1) one must assume too many unknowns to apply the Blanton or the Warpinski and Teufel models in their current state of development; and (2) the basalt fracture anisotropy introduces the significant uncertainty that the responses of the individual transducer gauges behave semi-independently and, collectively, do not represent elliptical deformation of the surface of the rock core. However, one might find it useful to investigate the use of some of these models in an attempt to gain further insight into the behavior of fractured rocks under stress relief conditions. 
Table 4. Summary of seismic velocities and apparent elastic properties for each subcore at $0.1 \mathrm{GPa}$ confining pressure.

\begin{tabular}{|c|c|c|c|c|c|c|c|c|c|}
\hline Sample & $\begin{array}{l}\text { Density } \\
\left(\mathrm{g} / \mathrm{cm}^{3}\right)\end{array}$ & $\begin{array}{c}V_{P} \\
(\mathrm{~km} / \mathrm{s})\end{array}$ & $\begin{array}{c}V_{\mathrm{s}} \\
(\mathrm{km} / \mathrm{s})\end{array}$ & $\mathrm{V}_{P} / V_{\mathrm{s}}$ & $S$ & $\begin{array}{c}K \\
(\mathrm{GPa})\end{array}$ & $\begin{array}{c}\mu \\
(\mathrm{GPa})\end{array}$ & $L$ & $\begin{array}{c}E \\
(\mathrm{GPa})\end{array}$ \\
\hline BAS01-1 & 2.84 & 5.83 & 3.20 & 1.822 & 0.284 & 57.7 & 29.1 & 38.3 & 74.6 \\
\hline BASO1-2 & 2.86 & 5.72 & - & - & - & - & - & - & - \\
\hline BASO1-3 & 2.87 & 5.96 & 3.27 & 1.823 & 0.285 & 61.0 & 30.7 & 40.5 & 78.8 \\
\hline BASO1-4 & 2.79 & 5.60 & 3.08 & 1.818 & 0.283 & 52.2 & 26.5 & 34.6 & 67.9 \\
\hline BASO1-5 & 2.85 & 5.64 & 2,87 & 1.965 & 0.325 & 59.2 & 23.4 & 43.6 & 62.1 \\
\hline BAS04-1 & 2.87 & 6.00 & 3.05 & 1.967 & 0.326 & 67.7 & 26.7 & 49.9 & 70.8 \\
\hline BAS04-2 & 2.87 & 5.87 & - & - & - & - & - & - & - \\
\hline BAS04-3 & 2.82 & 5.65 & 2.83 & 1.996 & 0.333 & 59.9 & 22.6 & 44.8 & 60.1 \\
\hline BASO4-4 & 2.86 & 5.83 & - & - & - & - & - & - & - \\
\hline BAS04-5 & 2.97 & 6.23 & 3.12 & 1.997 & 0.333 & 76.8 & 28.9 & 57.5 & 77.1 \\
\hline BAS08-1 & 2.88 & 5.78 & 3.25 & 1.778 & 0.269 & 55.7 & 30.4 & 35.4 & 77.2 \\
\hline BAS08-2 & 2.89 & 5.81 & 3.22 & 1.804 & 0.278 & 57.5 & 29.9 & 37.5 & 76.5 \\
\hline BAS08-3 & 2.88 & 5.76 & 3.05 & 1.889 & 0.305 & 59.8 & 26.8 & 42.0 & 69.9 \\
\hline BAS08-4 & 2.93 & 5.91 & 2.90 & 2.038 & 0.341 & 69.5 & 24.7 & 53.1 & 66.1 \\
\hline BAS08-5 & 2.91 & 5.83 & 2.93 & 1.990 & 0.381 & 65.6 & 25.0 & 48.9 & 66.5 \\
\hline BAS11-1 & 2.82 & 5.35 & 2.90 & 1.845 & 0.292 & 49.9 & 23.7 & 33.2 & 61.2 \\
\hline BAS $11-2$ & 2.72 & 5.28 & 2.77 & 1.906 & 0.310 & 47.9 & 20.8 & 34.0 & 54.6 \\
\hline BASI1-3 & 2.84 & 5.62 & 3.03 & 1.855 & 0.295 & 54.8 & 26.0 & 37.5 & 67.4 \\
\hline BAS $11-4$ & 2.80 & 5.50 & 2.88 & 1.910 & 0.311 & 53.6 & 23.2 & 38.2 & 60.7 \\
\hline BAS11-5 & 2.83 & 5.68 & 2.95 & 1.925 & 0.315 & 58.5 & 24.6 & 42.1 & 64.8 \\
\hline BAS12-1 & 2.82 & 5.75 & - & - & - & - & - & - & $=$ \\
\hline BAS12-2 & 2.84 & 5.55 & 3.00 & 1.850 & 0.294 & 53.4 & 25.5 & 36.3 & 66.1 \\
\hline BAS12-3 & 2.85 & 5.38 & 3.07 & 1.752 & 0.259 & 46.7 & 26.8 & 28.8 & 67.6 \\
\hline BAS12-4 & 2.85 & 5.72 & 3.06 & 1.869 & 0.300 & 57.7 & 26.7 & 39.9 & 69.4 \\
\hline BAS12-5 & 2.84 & 5.66 & 2.92 & 1.938 & 0.319 & 58.7 & 24.2 & 42.6 & 63.9 \\
\hline BAS15-1 & 2.93 & 6.14 & 3.51 & 1.749 & 0.257 & 62.3 & 36.1 & 38.3 & 90.8 \\
\hline BAS15-2 & 2.94 & 6.14 & 3.51 & 1.749 & 0.257 & 62.4 & 36.2 & 38.3 & 90.9 \\
\hline BAS $15-3$ & 2.92 & 6.13 & 3.33 & 1.841 & 0.291 & 66.5 & 32.4 & 45.0 & 83.6 \\
\hline BAS $15-4$ & 2.93 & 6.10 & 2.95 & 2.068 & 0.347 & 74.9 & 25.4 & 57.9 & 68.6 \\
\hline BAS $15-5$ & 2.93 & 6.10 & 3.22 & 1.894 & 0.307 & 68.5 & 30.4 & 48.3 & 79.4 \\
\hline
\end{tabular}

Note: $L=$ Lame's constant; $S=$ Poisson's ratio; $E=$ Young's modulus; $K=$ bulk modulus; $\mu=$ shear modulus.

In summary, the strain recovery curves recorded for each of the 15 basalt core samples during Leg 123 reflect the result of two competing time-dependent processes: anelastic strain recovery and pore pressure recovery. If these were the only two processes to influence the gauge responses, then one might expect that, given the additional information required, the Warpinski and Teufel theoretical model could be used to determine consistent stress orientations (assuming accurate paleomagnetic core orientations) and reliable stress magnitudes. However, superimposed upon these competing processes is their respective interaction with the preexisting fractures intersecting each core.

Evidence from our experiments and observations suggests that these fractures have a dominating influence on the characteristics of the recovery curves and that their effects are complex.

Therefore, until such time as theoretical models can be developed to cope with anelastic strain recovery of fractured rocks, results from basalt cores should be interpreted with considerable caution. If basalts are likely to be the only suitably lithified material available from ODP drilling sites, then core samples need to be selected carefully to exclude those exhibiting signs of preexisting fracturing.

\section{ACKNOWLEDGMENTS}

The authors gratefully acknowledge the financial support provided to each institute by the NERC Ocean Drilling Program Special Topic Grants Committee, without which this work would not have been possible. Also, the technical assistance and advice given by the staff at the BP Research Centre during the early stages of this project are fully acknowledged. Much of the macrocharacterization and dynamic elastic property measurement was conducted by Kevin Jones, for which we are duly grateful. Thanks also to John Ludden and Felix Gradstein, the two Co-Chief Scientists; Andrew Adamson, the ODP Staff Scientist; James Ogg and Kazuto Kodama, who performed the paleomagnetic core orientation measurements; and all the Leg 123 scientific party and crew of JOIDES Resolution.

\section{REFERENCES}

Birch, F., 1960. The velocity of compressional waves in rocks to 10 kilobars. J. Geophys. Res., 65:1083-1102.

Blanton, L., 1983. The relationship between recovery deformation and in-situ stress magnitudes. Soc. Pet. Eng. Pap., No. 11624.

1989. Discussion of "A viscoelastic constitutive model for determining in-situ stress magnitudes from anelastic strain recovery of core." Soc, Pet. Eng. Prod. Eng. Pap., 281-287.

Blanton, L., and Teufel, L. W., 1983. A field test of the strain recovery method of stress determination in Devonian shale. Soc. Pet. Eng. Pap., No. 12304.

1986. A critical evaluation of recovery deformation measurements as a means of in situ stress determinations. Soc. Pet. Eng. Pap., No. 15217.

Brereton, N. R., Chroston, P. N., Evans, C. J., Hudson, J. A., and Whitmarsh, R. B., 1990. Stress in the oceanic crust: anelastic strain recovery and elastic properties of basaltic rocks. Br. Geol. Surv. Tech. Rep., WK/9O/10.

Brereton, N. R., and Evans, C. J., 1989. Rock stress orientations from borehole breakouts. In Louwrier, K., Staroste, E., and Garnish, J. D. (Eds.), European Geothermal Update. Proc. 4th Int. Sem. Results EC Geotherm. Energy Res. Demonstr. (April 1989). Florence (Kluwer Academic Publishers), 213-231.

Charlez, P., Hamamdjian, C., and Despax, D., 1986. Is the microcracking of a rock a memory of its initial state of stress? Proc. Int. Symp. Rock Stress Measurements (Stockholm), 341-350.

Cheng, C. H., and Toksoz, M. N., 1979. Inversion of seismic velocities for the pere aspect ratio spectrum of a rock. J. Geophys. Res., 84:7533-7543.

Crampin, S., McGonigle, R., and Bamford, D., 1980. Estimating crack parameters from observations of P-wave velocity anisotropy. Geophysics, 45:345-360.

Dally, J. W., and Riley, W. F., 1978. Experimental Stress Analysis: New York (McGraw-Hill). 
Dey, T. N., and Kranz, R. L., 1988. State of stress and relationship of mechanical properties to hydrothermal alteration at Valles Caldera core hole 1, New Mexico. J. Geophys. Res., 93:6108-6112.

Dyke, G. C., 1989. In situ stress indicators for rock at great depth. [Ph.D. thesis]. Univ. of London.

El Rabaa, A. W., 1989. Determination of the stress field and fracture direction in the Danian Chalk. In Maury, V., and Fourmaintraux, D. (Eds.), Rock at Great Depth: Rotterdam (Balkema).

El Rabaa, A. W., and Meadows, D. L., 1986. Laboratory and field application of the strain relaxation method. Soc. Pet. Eng. Pap., No. 15072.

Embleton, B.J.J., 1981. A review of the Paleomagnetism of Australia and Antarctica. In McElhinny, M. W., and Valencio, D. A. (Eds.), Paleoreconstruction of the Continents. Am. Geophys. Union Geodyn. Ser., 2:77-92.

1984. Continental paleomagnetism. In Veevers, J. J., et al. (Eds.), Phanerozoic Earth History of Australia: Oxford (Oxford Univ. Press), 11-16.

Engelder, T., 1984. The time-dependent strain relaxation of Algerie granite. Int. J. Rock Mech. Min. Sci. Geomech. Abstr., 21:63-73.

Frocht, M. M., 1948. Photoelasticity: New York (Wiley).

Holcomb, D. J., and McNamee, M. J., 1984. Displacement gauge for the rock mechanics laboratory. Sandia Nat. Lab. (Tech. Rep.) SAND, No. 84-0651.

Hyett, A. J., 1990. The potential state of stress in a naturally fractured rock mass. [Ph.D. thesis]. Univ. of London.

Jaeger, J. S., and Cook, N.G.W., 1979. Fundamentals of Rock Mechanics (3rd ed.): New York (Chapman and Hall).

Kowallis, B. J., and Wong, H. F., 1983. Microcrack study of granitic cores from Illinois deep borehole UPH3. J. Geophys. Res., 88:7373-7380.

Lacy, L. L., 1987. Comparison of hydraulic fracture orientation techniques. Soc. Pet. Eng. Form. Eval. Pap., 66-76.

Ludden, J. N., Gradstein, F. M., et al., 1990. Proc. ODP. Init. Repts., 123: College Station, TX (Ocean Drilling Program).

Newmark, R. L., Anderson, R. N., Moos, D., and Zoback, M. D., 1985. Structure, porosity and stress regime of the upper oceanic crust: sonic and ultra-sonic logging of DSDP Hole 504B. Tectonophysics, 118:142.

Nur, A., and Simmons, G., 1970. The origin of small cracks in igneous rocks. int. J. Rock Mech. Min. Sci. Geomech. Abstr., 7:307-314.

Sarda, J. P., and Perreau, P. J., 1989. Determination of in-situ stress parameters from measurements on cores. CEC Rep., Brussels-Luxembourg, EUR 12514.

Strickland, F., and Ren, N., 1980. Predicting the in-situ stress for deep wells using the differential strain curve analysis. Soc. Pet. Eng. Pap., No. 8954.

Swolfs, H. S., 1975. Determination of in-situ stress orientation in a deep gas well by strain relief techniques. Unpubl. Terra Tek Rept., TR-7543.

Teufel, L. W., 1982. Prediction of hydraulic fracture azimuth from anelastic strain recovery measurements of oriented core. In Goodman, R., and Heuze, F., (Eds.), Proc. 23rd U.S. Natl. Rock Mech. Symp., 238-246.
1983. Determination of in situ stress from anelastic strain recovery measurements of oriented cores. Soc. Pet. Eng. Pap., No. 11649.

1984. Determination of the principal horizontal in situ stress directions from anelastic strain recovery measurements of oriented cores from deep wells: applications to the Cotton Valley formation of east Texas. Geomechanics, 57:55-63.

1986. In-situ stress measurements in inclined holes in the North Sea: applications to water flooding and enhanced oil recovery. Soc. Pet. Eng. Pap., No. 13986.

Teufel, L. W., and Warpinski, N. R., 1984. Determination of in situ stress from anelastic strain recovery measurements of oriented cores: comparison to hydraulic fracture stress measurements in the Rollins Sandstone, Piceance Basin, Colorado. Sandia Nat. Lab. (Tech. Rep.) SAND, No. 84-0512C.

Toksöz, M. N., Cheng, C. H., and Timur, A., 1976. Velocities of seismic waves in porous rocks. Geophysics, 41:621-645.

Voight, B., 1968. Determination of the virgin state of stress in the vicinity of a borehole from measurements of a partial anelastic strain tensor in drill cores. Feismech. Ingenieurgeol., 6:201-215.

Walsh, J. B., 1965. The effect of cracks on the compressibility of rock. J. Geophys. Res., 70:381-389.

Warpinski, N. R., and Teufel, L. W., 1986. A viscoelastic constitutive model for determining in situ stress magnitudes from anelastic strain recovery of core. Soc. Pet. Eng. Pap., No. 15368.

1989a. In-situ stresses in low permeability nonmarine rocks. $J$. Pet. Tech., 405-414.

1989 b. A viscoelastic constitutive model for determining in situ stress magnitudes from anelastic strain recovery of core. Soc. Pet. Eng. Product. Eng. Pap., 272-280.

1989c. Authors reply to "Discussion of 'A viscoelastic constitutive model for determining in situ stress magnitudes from anelastic strain recovery of core'," Soc. Pet. Eng. Product. Eng. Pap., 287-289.

Wolter, K. E., and Berkhemer, H., 1989. Time dependent strain recovery of cores from the KTB-deep drill hole. Rock Mech. Rock Eng., 22:273-287.

Yasunaga, K., 1989. Anelastic strain recovery [M.Sc. thesis]. Univ. of London.

Zoback, M. D., Moos, D., Mastin, L., and Anderson, R. N., 1985. Well bore breakouts and in situ stress. J. Geophys. Res, 90:5523-5530.

Zoback, M. L., Zoback. M. D., Adams, J., Assumpêio, M., Bell, S., Bergman, E. A., Blümling, P., Brereton, N. R., Denham, D., Ding, J., Fuchs, K., Gay, N., Gregersen, S., Gupta, H. K., Givishiani, A., Jacob, K., Klein, R., Knoll, P., Magee, M., Mercier, J. L., Müller, B. C., Paquin, C., Rajendran, J., Stephensson, O., Suarez, G., Suter, M., Udas, A., Xu, Z. H., and Zhizhin, M., 1989. Global patterns of intraplate stress: a status report on the world stress map project of the International Lithosphere Program. Nature, 241:291-298.

Date of initial receipt: 15 May 1990

Date of acceptance: 19 August 1991

Ms 123B-132 